This item was submitted to Loughborough's Research Repository by the author.

Items in Figshare are protected by copyright, with all rights reserved, unless otherwise indicated.

\title{
Evidence review for the 2016 International Ankle Consortium consensus statement on the prevalence, impact and long-term consequences of lateral ankle sprains
}

\section{PLEASE CITE THE PUBLISHED VERSION}

http://dx.doi.org/10.1136/bjsports-2016-096189

\section{PUBLISHER}

BMJ Publishing Group / @ The Authors

VERSION

AM (Accepted Manuscript)

\section{PUBLISHER STATEMENT}

This work is made available according to the conditions of the Creative Commons Attribution-NonCommercialNoDerivatives 4.0 International (CC BY-NC-ND 4.0) licence. Full details of this licence are available at: https://creativecommons.org/licenses/by-nc-nd/4.0/

\section{LICENCE}

CC BY-NC-ND 4.0

\section{REPOSITORY RECORD}

Gribble, Phillip A., Christopher M. Bleakley, Brian Caulfield, Carrie L. Docherty, Francois Fourchet, Daniel TikPui Fong, Jay Hertel, et al.. 2019. "Evidence Review for the 2016 International Ankle Consortium Consensus Statement on the Prevalence, Impact and Long-term Consequences of Lateral Ankle Sprains". figshare. https://hdl.handle.net/2134/21876. 


\section{British Journal of Sports Medicine}

\section{Evidence Review for the 2016 International Ankle Consortium Consensus Statement on the Prevalence, Impact and Long-term Consequences of Lateral Ankle Sprains}

\begin{tabular}{|r|l|}
\hline Journal: & British Journal of Sports Medicine \\
\hline Manuscript ID & bjsports-2016-096189.R1 \\
\hline Article Type: & Narrative Review \\
\hline Date Submitted by the Author: & 05-May-2016 \\
\hline Complete List of Authors: & $\begin{array}{l}\text { Gribble, Phillip; University of Kentucky, Department of Rehabilitation } \\
\text { Science } \\
\text { Bleakley, Chris; University of Ulster, Sport and Exercise Science Research } \\
\text { Institute } \\
\text { Caulfield, Brian; University College Dublin, School of Physiotherapy } \\
\text { Docherty, Carrie; Indiana University Bloomington } \\
\text { Fong, Daniel; Loughborough University } \\
\text { Fourchet, Francois; Hopital de la Tour } \\
\text { Hertel, Jay; University of Virginia, Kinesiology Program } \\
\text { Hiller, Claire; University of Sydney, Physiotherapy } \\
\text { Kaminski, Thomas; University of Delaware, Depr of Health, Nutrition and } \\
\text { Exercise Sciences } \\
\text { McKeon, Patrick; Ithaca College } \\
\text { Refshauge, Kathryn; University of Sydney, Health Sciences } \\
\text { Verhagen, Evert; EMGO Institute for Health and Care Research, Public and } \\
\text { Occupational Health } \\
\text { Vicenzino, Bill (Guglielmo); University of Queensland, Physiotherapy } \\
\text { Wikstrom, Erik; University of North Carolina at Chapel Hill } \\
\text { Delahunt, Eamonn; University College Dublin, School of Public Health, } \\
\text { Physiotherapy and Population Science }\end{array}$ \\
\hline Keywords: & \begin{tabular}{l} 
Ankle, Public health \\
\hline
\end{tabular} \\
\hline
\end{tabular}


Evidence Review for the $\mathbf{2 0 1 6}$ International Ankle Consortium Consensus Statement on the Prevalence, Impact and Long-term Consequences of Lateral Ankle Sprains

\author{
Phillip A Gribble ${ }^{1}$ \\ Chris Bleakley ${ }^{2}$ \\ Brian Caulfield ${ }^{3}$ \\ Carrie Docherty ${ }^{4}$ \\ François Fourchet ${ }^{5}$ \\ Daniel Tik-Pui Fong ${ }^{6}$ \\ Jay Hertel $^{7}$ \\ Claire Hiller $^{8}$ \\ Thomas Kaminski ${ }^{9}$ \\ Patrick McKeon ${ }^{10}$ \\ Kathryn Refshauge ${ }^{8}$ \\ Evert Verhagen ${ }^{11}$ \\ Bill Vincenzino $^{12}$ \\ Erik Wikstrom $^{13}$ \\ Eamonn Delahunt ${ }^{14}$
}

1. University of Kentucky, College of Health Sciences, Lexington, Kentucky, USA

2. Ulster University, Department of Life and Health Sciences, Jordanstown, Carrickfergus, UK

3. University College Dublin, Insight Centre for Data Analytics, Dublin, Ireland

4. Indiana University, College of Public Health, Bloomington, Indiana, USA

5. Hôpital La Tour, Physiotherapy Department, Geneva, Switzerland

6. Loughborough University, National Centre for Sport, Exercise and Health Sciences, East Midlands School of Sport, Exercise and Health Sciences, Loughborough, Leicestershire, UK

7. University of Virginia, Departments of Kinesiology and Orthopaedic Surgery, Charlottesville, Virginia, USA

8. University of Sydney, College of Health, Sydney, New South Wales, Australia

9. University of Delaware, Department of Kinesiology and Applied Physiology, Newark, Delaware, USA

10. Ithaca College, Department of Exercise and Sport Sciences, Ithaca, New York, USA

11. VU University Medical Center, Department of Public and Occupational Health, Amsterdam, Netherlands

12. University of Queensland, School of Health and Rehabilitation Sciences: Physiotherapy, Brisbane, Queensland, Australia

13. University of North Carolina at Chapel Hill, Department of Exercise \& Sport Science, Chapel Hill, North Carolina, USA 
8

39

40

41

42

43

44

45

46

47

48

49

50

51

52

53

54

55

56

57

58

59

60

14. University College Dublin, School of Public Health, Physiotherapy and Sports Science, Dublin, Ireland

Corresponding Author: Phillip Gribble, PhD, ATC, FNATA

Charles Wethington, Jr. Building, Room 206C 900 South Limestone

College of Health Sciences University of Kentucky

Lexington, KY 40536-0200

phillip.gribble@uky.edu

17 Keywords: Public health, post-traumatic osteoarthritis, quality of life 18 
8 9 10
1 Title: Evidence Review for the 2016 International Ankle Consortium Consensus Statement 2 on the Prevalence, Impact and Long-term Consequences of Lateral Ankle Sprains 3 4 5 Abstract

6 Lateral ankle sprains (LASs) are the most prevalent musculoskeletal injury in physically active 7 populations. They also have a high prevalence in the general population and pose a substantial 8 health care burden. The recurrence rates of LAS are high, leading to a large percentage of LAS 9 patients developing chronic ankle instability (CAI). This chronicity is associated with decreases 10 in physical activity levels and quality of life and associates with increasing rates of ankle post11 traumatic osteoarthritis, all of which generate financial costs that are larger than many have 12 realized. The literature review that follows expands this paradigm and introduces emerging areas 13 that are that should be prioritized for continued research, supporting a companion position 14 statement paper that proposes recommendations for utilizing this summary of information, as 15 well as needs for specific future research. 
1 Musculoskeletal injuries have the potential to outweigh the health benefits of participation in

2 physical activity and organized sport, and the perceived risk of injury could also act as a

3 deterrent to future participants.[1 2] Lateral ankle sprains (LASs) are the most prevalent

4 musculoskeletal injury in physically active populations. They also have a high prevalence in the

5 general population and pose a substantial health care burden. The injury mechanism is

6 characterized by a high velocity inversion and internal rotation of the ankle/foot complex. The

7 treatment for acute LAS is quite variable, with many patients returning to activity in a short

8 period of time; however, half of the population may never seek initial care.

\section{The recurrence rates of LAS are high, leading to a large percentage of LAS patients} developing chronic ankle instability (CAI). The lingering ankle instability contributes to ongoing disability and sensorimotor control deficits, which associate with decreased physical activity and quality of life. Not surprisingly, we are seeing that patients with a history of LAS and CAI dominate ankle joint post traumatic osteoarthritis (PTOA) cases, which comprise the majority of the ankle joint OA surgical cases. Additionally, the onset of ankle joint PTOA is occurring earlier in the lifespan than most would assume.

While the direct costs for treatment of an isolated acute LAS are relatively low, compounding these costs are the indirect costs accruing from follow-up care and time loss.

Considering that LAS injury is the most prevalent musculoskeletal injury in physically active populations, the societal costs are larger than most comprehend. As these costs for management of acute LAS are combined with the costs of managing the loss of physical activity and treatments for likely onset and care for ankle joint PTOA, it is easy to formulate the health care 22 burden that emerges from a seemingly "simple" LAS injury. 
8

9
2 introduces emerging areas that are that should be prioritized for continued research. In a

3 companion position statement paper, the Executive Committee of the International Ankle

4 Consortium proposes recommendations for utilizing this summary of information, as well as

5 needs for specific future research based on this evidence review that follows. Therefore, the

6 Executive Committee of the International Ankle Consortium presents this review of the evidence

7 that demonstrates that LAS, and the development of CAI, serve as a conduit to a significant

8 global health care burden. We illustrate this paradigm as a mechanism to promote efforts to

9 improve prevention and early management of LAS. We believe this will reduce the prevalence of

$10 \mathrm{CAI}$ and associated sequelae that have led to the broader public health burdens of decreased

11 physical activity and early onset ankle joint PTOA. Ultimately, this can contribute to healthier

12 lifestyles and promotion of physical activity. Our review of evidence is organized into two
Comment [PG1]: Add in citation from BJSM that will follow once its available 
1 Section A: Establishing Lateral Ankle Sprain Prevalence and Burden

\section{Defining Lateral Ankle Sprain}

3 LAS is the most common lower limb musculoskeletal injury in physically active

4 persons.[3] Acute LAS has been defined by Delahunt et al[4] and endorsed by the International

5 Ankle Consortium[5-7] as "an acute traumatic injury to the lateral ligament complex of the ankle

6 joint as a result of excessive inversion of the rear foot or a combined plantar flexion and

7 adduction of the foot."

$8 \quad$ Mechanism of injury

$9 \quad$ Ankle sprains are particularly prevalent in field and court sports.[8] In an attempt to

10 develop a comprehensive understanding of the mechanisms of LAS in football, Andersen et al[9]

reviewed videotape recordings of 26 ankle sprains in Norwegian and Icelandic elite football from

12 the 1999-2000 season. They reported that the two most frequent injury mechanisms were: (1)

player-to-player contact with impact by an opponent on the medial aspect of the leg just before a vulnerable, inverted position; or (2) forced plantar flexion where the injured player hit the opponent's foot when attempting to shoot or clear the ball. Both of these mechanisms can be described as contact mechanisms of injury. However, qualitative analysis and reporting of injury mechanisms based on visual inspection of recorded injuries is not without limitations.

Furthermore, non-contact mechanisms of ankle sprain are reported to be more common than contact mechanisms of injury.[8]

Fong et al[10] reported the first-ever kinematic analysis of a LAS, which occurred accidentally during testing in their research laboratory. A male athlete performing a series of cutting test trials incurred a LAS during the $4^{\text {th }}$ test trial. During the injury sustaining trial, the 
1 ankle was $7^{\circ}$ more internally rotated and $6^{\circ}$ more inverted at initial contact when compared with

2 the preceding three "normal" test trials in which no adverse result occurred. The injury trial was

3 characterized by a rapid inversion and internal rotation which was initiated 0.06 seconds

4 following initial contact. Interestingly, in contrast to previously purported mechanisms of injury,

5 dorsiflexion was observed throughout the injury trial. A number of other authors have reported

6 the kinematic patterns observed during accidental LASs incurred during controlled laboratory

7 testing.[11-13] All observations confirmed the presence of a rapid increase in inversion and

8 internal rotation with or without the presence of plantar flexion. Thus, it can be considered that

9 LASs occur as a consequence of a sudden rapid inversion and internal rotation loading of the

10 foot and ankle complex irrespective of sagittal plane position.

\section{More recently, Mok et al[14] and Fong et al[15] used a model-based image-matching} motion analysis technique to describe the kinematic characteristics of un-calibrated video recordings of ankle joint sprains incurred during live sporting events. Mok et al[14] reported on two LASs incurred during the 2008 Beijing Summer Olympic Games. The injuries occurred during the women's high jump qualification round and a field hockey match. For the high jump injury, the ankle joint was $30^{\circ}$ inverted, $28^{\circ}$ internally rotated, and $5^{\circ}$ plantar flexed at initial contact. Following initial contact there was a sudden rapid increase in inversion (maximum = $142^{\circ}$ ) and internal rotation $\left(\right.$ maximum $\left.=37^{\circ}\right)$. The field hockey injury was a contact mechanism, whereby the defending player accidentally stood on the attacking player's foot provoking an inversion moment and subsequent LAS. Additionally, Fong et al[15] described the kinematic characteristics of LASs recorded during five televised tennis matches. In all instances, the ankle joint was inverted at the time of initial contact, which is a vulnerable position and posited as an inciting mechanism of LAS.[16] Furthermore, peak inversion was noted to occur rapidly after 
1 initial contact (typically $0.09-0.13$ seconds).

2

$3 \quad$ Epidemiology of Lateral Ankle Sprain

5 physically active populations. Commonly, these injuries are considered only to be an issue for 6 athletes; but as the evidence shows, LASs are an injury that impacts many aspects of physical 7 activity. Additionally, the distribution of LASs within the general population is quite large as 8 demonstrated from emergency department (ED) data. It is important to demonstrate the 9 prevalence of LAS throughout society to establish the foundation for the public healthcare burden we present in this paper.

There is an abundance of epidemiological data delineating patterns of ankle injury in sporting activities. In 2007, Fong et al[17] reviewed 227 epidemiological studies, across 70 sports, involving a total of 201,600 individuals. In 24 of the 70 included sports (34\%), the ankle joint was the most commonly injured body part. A recently published systematic review by Doherty et al[8] included a meta-analysis of prospective studies and provided pooled incidence figures, sub-grouped by sport, age and gender. In conjunction with earlier reports,[17] indoor/court sports had the highest incidence rates estimated as 7 ankle sprains per 1,000 exposures.[8] There were also differences according to athletes' gender, with higher incidences estimated in females (13.6 per 1,000 exposures) compared to males (6.94 per 1,000 exposures). Incidence rates also varied across age cohorts, with the highest figure of 2.85 ankle sprains per 1,000 exposures reported in young athletes (under 12 years of age), followed by adolescents (aged 12-18 years) (1.94 per 1,000 exposures), then adults (0.72 per 1,000 exposures).[8] In both 
1 reviews, there was consistent evidence that the majority of ankle injuries were diagnosed as 2 sprains; of which $80 \%-90 \%$ were LASs.

Although it is interesting to compare data across multiple sports and nationalities, pooled

4 incidence figures, such as those presented by Doherty et al[8] can be limited by study

5 heterogeneity. Prospective injury data extracted from large regional datasets may be more

6 reliable by ensuring consistency in study methods, injury definitions, and medical verification

7 over time. The National Collegiate Athletic Association (NCAA) Injury Surveillance System

8 (ISS) has captured injury data across 16 collegiate sports over the past 27 years in the United

9 States. Using this database, Hootman et al[18] report that ankle ligament sprains are the most common injury in NCAA sports, accounting for $15 \%$ of all reported injuries, with an overall incidence of 0.83 sprains per 1,000 athletic exposures (AE). Their data also show that incidence rates differ across sports, with the highest figures reported in basketball and soccer. Interestingly their reported rates were consistent across gender cohorts, with similar figures in female (1.15 ankle sprains per 1,000 AE) and male basketball players (1.3 ankle sprains per 1,000 AE), and in female (1.3 ankle sprains per 1,000 AE) and male soccer players (1.24 ankle sprains per 1,000 AE).[18] High participation in sports such as soccer (estimated 265 million soccer players worldwide[19]) or basketball (estimated 450 million basketball players worldwide[20]) provides further context to the global burden associated with ankle sprains in sport.

It is important to consider that other physically active populations, such as military personnel, are also at high risk of ankle sprain. Two of the largest studies in this area have used retrospective audits of injury data recorded (prospectively) over a 7-9 year period in the United

2 States, with the incidence of ankle sprains reported to be between 34.95[21] to 45.14[22] sprains per 1000 person-years. Based on a conservative estimate of 100 exposures per year, these equate 
1 to approximately 0.35 to 0.45 ankle sprains per 1000 exposures, figures that are comparable to

2 many sporting populations such as softball, baseball, and both ice and field hockey.[18]

Another important patient cohort to consider is the general population presenting to an

4 ED in the early stages post- ankle injury. In the United Kingdom (UK), 3-5\% of all ED

5 presentations are for LAS, [23 24] equating to 5600 daily incidents[23] or 1-1.5 million visits

6 annually.[24] One of the first audits of ED attendances was undertaken in a single region of

7 Denmark in 1994 and estimated an incidence of 7.0 ankle sprains per 1000 person-years.[25] A

8 decade later, slightly lower incidence rates of 5.2 per 1000 people per year were estimated based

9 on data captured from EDs across four large health districts in the UK.[26] Interestingly, this

10 study also noted marked age-sex differences, with the highest incidence figures reported in girls 11 aged 10-14 years (12.8 per 1000 person-years).

Two studies in the United States accessed ED data sets from the National Electronic Injury Surveillance System (NEISS).[3 27] Lambers et al[27], using data from 119,815 patient presentations in a single year, reported that ankle sprains were the most common reason for presenting to an ED, estimating an incidence of 2.06 ankle sprains per 1000 person years $(95 \%$ CI, 181-230). Similarly, Waterman et al[3] reported rates of 2.15 per 1000 person-years during a four-year review. A 25-year review of the Dutch Injury Surveillance System undertaken by Kemler et al[28] is the largest ED data set analyzed to date. Interestingly, they reported a steady decline in ankle sprains between 1986 and 2010, from 3.0 per 1000 person-years, down to 2.1 per 1000 person-years, but these figures are generally consistent with those reported in the United States.[3 27] In the same report Kemler et al[28] also analyzed data from a 10-year National Survey in the Netherlands. Although separate figures were not available for ankle sprains, an interesting finding was that ankle injury rates more than doubled over a 10 -year 
1 period, from 8.2 per 1000 person-years in 2000 , up to 17.5 in 2010 . This likely indicates that

2 LASs are still occurring at a high rate, but fewer individuals may be seeking treatment from an $3 \quad$ ED

4

5 Financial Burden

Sports injuries in general and ankle sprains in particular, have a significant financial impact on society. Most injuries require clinical care, and may also lead to production loss due to work absenteeism and disablement. From a clinical perspective, the sports time lost, and the short- and long-term consequences, are a good indicator of the severity of an injury. However, economic evaluations aid policy makers in their decisions to place focus on specific sports, injuries and interventions. An economic interpretation of injury severity in terms of direct (healthcare) costs and indirect (productivity loss) costs provides a single understandable figure that unifies many of the clinical injury outcomes. A description and valuation of costs is also vital for analysis of intervention effectiveness to determine if an intervention comes with a tolerable financial investment relative to a favorable clinical outcome. Weighting these factors in a cost-effectiveness analysis provides a tool to quantify the required investment to prevent, effectively diagnose or treat LAS.[29-36] However, we will restrict ourselves here to a rough description of the costs associated with ankle sprains. For an expanded background on the methodology employed in economic evaluations in sports medicine, we refer to text books on this topic.[37 38] It should be noted that there are large differences in valuation of costs and market prices between countries, and as such cost data from different countries should be compared with caution. Also, cost data are subject to change over time due to factors such as inflation, changes in the healthcare system, or effectiveness of provided care. Consequently, we 
1 have chosen only to report on costs published after the year 2000 to provide the most

2 contemporary overview to date of the financial burden of LAS.

3 Societal costs

4 The most comprehensive cost perspective is the 'societal' perspective, which represents

5 the costs of an injury for society regardless of who pays. Costs from a societal perspective

6 include the out-of-pocket expenses for the injured individual, the costs for provided clinical care,

7 as well as the costs for the employer. We employ this societal perspective in this section, with

8 sub-divisions solely in direct and indirect costs. As such, data derived from insurance registries

9 are not discussed here.

10 In the United States, Knowles et al[39] prospectively calculated the costs associated with

musculoskeletal injuries in high school athletes. This study is unique as in addition to the short-

term direct and indirect costs they also attached a monetary value to lost health in the long-term mean societal costs for a joint sprain $(\$ 9,196 ; 95 \%$ CI $\$ 6,856$ to $\$ 11,536)$ and ankle injuries $(\$ 11,925 ; 95 \%$ CI $\$ 10,188$ to $\$ 13,662)$ were reported. Given that ankle sprains are among the most commonly reported injuries, it is likely that the mean societal costs for LASs in United States high school athletes reside within this range.

These cost are higher than what is reported in studies that only include the short-term costs of ankle sprains, i.e. costs incurred from the moment of injury occurrence to recovery.[31 $3640]$ Cooke et al[40] reported the societal cost of ankle sprains in a population of British ED patients to be $£ 940$. This amount is comparable to what is found in the Netherlands, where the costs of ankle sprains presenting at an ED are calculated to be $€ 823$.[41] It may be clear that patients who require hospitalization after emergency care have higher costs than patients who do 
1 not require further hospital care, respectively $€ 6,217$ and $€ 842$ in the Dutch situation.[41] Those

2 patients who present at an ED have in general more severe injuries, which can be illustrated by

3 the societal costs of ankle sprains as reported by Verhagen et al[36] and Hupperets et al[31] Both

4 studies reported on the costs of all ankle sprains sustained by a sporting population. Hupperets et

$5 a l[31]$ reported specifically on the costs associated with recurrent ankle sprains that were

6 sustained in the year after athletes were deemed fit to return to play. The costs of these

7 recurrences were estimated at $€ 447$ per injury, by which it can be concluded that both primary

8 and secondary ankle sprains are associated with a significant financial burden and that

9 prevention is duly warranted. 


\section{Direct costs}

Part of the societal cost comprises the direct costs of injury due to consumed healthcare.

3 These costs include, among others, the consultation costs of caregivers, the operational costs of 4 diagnostics, prescribed and over-the-counter medications, etc. Presentation of direct costs of 5 ankle sprains provides insight into the concrete burden to the healthcare system. Cooke et al[40] 6 describe the total direct costs of standard care for ankle sprains presenting at British EDs to be $7 £ 135$. Verhagen et al.[36] valued these costs at $€ 43$, and Hupperets et al.[31] at $€ 61$. Naturally 8 the direct costs of ankle sprains treated at EDs are lower, while specialized care provided in a 9 clinic is generally more elaborate and expensive. It is impossible to provide a breakdown of the 10 healthcare consumption per injury, but what is generally described is that most direct costs go 11 into consultation with caregivers of which most are physiotherapists.[31 364041$]$ 12 Indirect costs

(3)

\section{In addition to the direct healthcare costs associated with acute LASs, these injuries are} also linked to indirect costs associated with time lost from activities. In sport and military settings, this impact is intuitive as it means time lost in training and likely a decrease in either game or combat readiness. However, in a private and business setting, the injury creates time lost from leisure time and work. Both carry a financial impact related to a loss of paid (work) and unpaid (leisure time) productivity, and both should be considered when describing the burden of LAS from a societal economical perspective. Naturally, when only interested in the cost perspective from an employer's point of view, time lost from unpaid work is not a meaningful measure; albeit the side note should be made that quality leisure time has been linked to increased vitality and productivity, by which a loss of leisure time is entangled to a financial burden for the employer nonetheless. 
Indirect injury costs due to lost productivity make up $70 \%$ to $90 \%$ of the total costs of

2 ankle sprains.[31 323639 40] Within the general population of the UK, Cooke et al[40]

3 observed an average of 6.9 days of paid work lost due to ankle sprains treated by means of

4 standard care, adding at least an additional $£ 805$ pounds in lost productivity costs for each ankle

5 sprain to the overall costs, compared to $£ 135$ of direct healthcare costs. Specifically in sports,

6 Verhagen et al[36] demonstrated that ankle sprains sustained by Dutch recreational volleyball

7 players led to an average of 2.3 days of working time lost and 29.8 hours of unpaid leisure time

8 lost per injury. These times were economically valued, based on standardized rates, at a mean of

$9 € 318$ of indirect costs per injury. This was in contrast to $€ 43$ of direct healthcare costs per injury.

10 Similarly, Hupperets et al[31] showed that recurrent ankle sprains sustained in a general Dutch

11 sporting population lead to an average of $€ 385$ indirect costs in contrast to $€ 61$ of direct

12 healthcare costs. Unfortunately, a breakdown between paid and unpaid work was not given. ${ }^{51}$

Long-term costs

Most of the cost analyses reviewed above focus on the short-term treatment and management for LAS. However, as is discussed later in this review, there is a very high rate of re-injury and subsequent development of CAI. Additionally, the long-term consequences of ankle injury are being recognized with the rise of documented ankle joint degenerative disease; specifically, the onset of ankle joint PTOA. Patients with a history of LAS make up 70\% to $85 \%$ of the surgical cases for end-stage ankle joint PTOA.[44-47] Patients with CAI are at an increased risk of PTOA,[44 45 47-52] suggesting that CAI represents an important contribution to the early stages of ankle joint degeneration and may even be a key mediator driving the disease process. This will be discussed in greater detail in Section B of this consensus statement. 
Conservative management using a variety of physiotherapy techniques can be utilized for

2 CAI patients with successful restoration of self-reported outcomes and functional measurements.

3 [53-65] While the cost analyses for management and early rehabilitation for LAS have been

4 discussed previously in this section, to our knowledge, there has been little cost analyses of

5 conservative treatment for CAI patients. Additionally, we have no data to demonstrate that

6 conservative management is effective at improving indices of long-term success, such as quality

7 of life years. Therefore, while likely to improve the quality of life of CAI patients, it is difficult

8 to conclude what the cost effectiveness of conservative management (i.e. physiotherapy) is

9 relative to standard of care, which is often nothing.

As CAI progresses, and symptoms, such as lingering pain, instability and reduction in

function persist with or without physiotherapy, CAI patients may seek non-conservative management options in the form of surgical reconstruction. The modified Brostrom procedure is the most commonly employed surgical procedure, with consistent reporting of associated longterm successful outcomes.[66-70] A recent prospective comparative study concluded similar functional success between the suture anchor or the suture bridge techniques of the Brostrom procedure, but better cost effectiveness for the surgical event with the suture anchor technique.[66] However, there is little to no data that has assessed the comprehensive costing and quality of life analysis of these surgical techniques relative to conservative management for CAI. The direct surgical costs are greater than non-surgical management of ankle instability, introducing financial burden for potentially effective treatment for CAI patients that have failed with conservative management. However, more research is needed to consider the indirect costs and assessments of quality of life using long-term follow-ups to determine the extent to which 
1 these surgical techniques contribute to increasing or decreasing the financial burden of ankle 2 instability.

3 Unfortunately, an alarmingly high percentage of PTOA patients stem from the CAI 4 patient population.[44 4749 50] At present, ankle replacement via arthroplasty or arthrodesis 5 represent the few options available for patients with ankle degenerative disease once symptoms 6 become intolerable and activity levels are compromised. As with surgical reconstruction, there 7 are few studies that have compared conservative management for ankle OA with surgical fusion 8 or replacement for the ankle. Nwachukwu et al[71] performed a cost effectiveness analysis of 9 operative and non-operative treatments with an emphasis on incremental cost-effectiveness ratio 10 (ICER), which considers direct and indirect costs along with quality of life years. Their analysis 11 was based on the cost of ankle fusion $(\$ 16,754)$ and ankle replacement $(\$ 21,423)$ from the 2012

12 Nationwide Inpatient Sample from the United States. Ankle replacement procedures are more expensive than non-operative management, but this technique was optimal in $83 \%$ of the analyses when considering direct and indirect costs, along with factors that impact quality of life.[71] This means that the best option for patients with end stage OA is a very costly surgery. This surgery optimizes the quality of life and minimizes the indirect costs compared to conservative management in these patients. While ankle replacement is a successful treatment option, it presents a major financial burden that emerges from patients with a history of LAS.

\section{$\underline{\text { Section A Summary }}$}

Contact and non-contact mechanisms of LAS exist. An inverted position of the ankle joint at initial contact is a particularly vulnerable position and has been identified as a key characteristic feature of the LAS injury mechanism. There is clear evidence that LASs 
1 commonly occur during sporting activity. Incidence figures in excess of 2.0 LASs per $1000 \mathrm{AE}$

2 are consistently reported in popular field and court sports.[8] Incidence rates in sport also tend to 3 vary according to age and gender, with some of the highest figures reported in young/adolescent 4 female athletes.[8] As LASs also occur during activities of daily living it is important to 5 determine population based incidence rates. Estimates from EDs range from 2 to 7 ankle sprains 6 per 1000 person-years, but these figures may be an underestimation due to the growing number 7 of patients attending primary care practice or self-managing their ankle sprain.[43]

8 Contemporary figures suggest that the true incidence rate in the general population is around 5.5

9 times higher than figures derived from EDs.[28] To provide the most accurate estimate of 10 population-based incidence rates, epidemiology studies should focus on National Survey data that encompasses both medical and non-medically treated ankle sprains. While LAS is the most common injury sustained in the physically active population, the documented prevalence of LAS demonstrates this is not an injury associated exclusively with sporting and competitive athlete groups. Therefore, we must consider the financial costs that associate with the management and treatment for LAS, as well as the long-term consequences that persist.

Economic consequences of injury add a new layer of severity outcome measures to describe the burden of injury, aiding policy makers in their decisions to place focus on specific sports, injuries or interventions. Costs are described in direct (medical costs) and indirect (work time lost) costs, and can be described in the short- and long-term. In regards to LAS, the direct costs are, as with other injuries, lower than the indirect costs. Although cost estimates differ between countries, depending upon the different insurance and medical systems, the sheer magnitude of LAS make the societal costs substantial. Usually such estimations do not include the long-term consequences of LAS, providing a significant underestimation of the actual 
1 financial burden LAS poses to society. We have identified the current information that depicts

2 the direct and indirect costings, but more comprehensive assessments of LAS management and

3 treatment are still needed. It is likely that with more complete analyses across societies, we will

4 realize that our current figures are underestimated.

5

\section{Section B: Mid- and Long-Term Consequences of Lateral Ankle Sprains}

7 Development and Onset of CAI

As an isolated, acute injury, it is common to consider LAS an innocuous injury from which a patient can recover fairly quickly. However, a significant number of people experience ongoing problems including residual symptoms of instability, decreased function, and activity restrictions in the months and years following LAS. It is common for these patients to develop CAI, and experience a substantial re-injury rate. Additionally, what causes CAI to develop in some patients but not in others has not been established definitively. Subsequently, we will summarize hypotheses that are currently being considered Post-acute deficits following LAS

Most patients with LAS have resolution of primary inflammatory symptoms in a relatively short period of time with conservative treatment,[72-74] and a high likelihood of rapid return to activity.[75] Subsequently, there is an assumption that LAS is an inconsequential injury once the sub-acute phase has passed. However, the consideration for successful treatment of LAS does not usually extend beyond the assessment of return to activity. What is observed commonly in follow-up of LAS patients are lingering disabling symptoms including pain and decreased function.[76] 
2 cadets presenting with a total of 67 LAS of varying severity, $78 \%$ of the grade 1 and $48 \%$ of the 3 grade 2 or 3 LAS patients had returned to full military demands by 6 weeks, but with $28 \%$ of all 4 the patients still reporting pain. However, at a 6-month follow-up ( $n=61)$, only $72 \%$ of all LAS 5 patients presented with full function; and $25 \%$ of patients still reported pain.[77] Konradsen et

$6 a l[78]$, at the 7-year follow- up of 648 LAS patients, found $>30 \%$ still had pain, swelling, or

7 recurrent injury (three or more severe sprains/year). Among those reporting ankle disability at

8 the 7-year follow-up, $>70 \%$ felt functionally impaired.[78]

Retrospective assessment of the population with a history of previous LAS demonstrates lingering symptoms and functional deficits. It is worth noting that $32 \%$ to $74 \%$ of individuals with a previous history of LAS suffer chronic symptoms.[78-80] Hiller et al[81], in a systematic review of 55 papers that included patients with recurrent ankle sprain history (at least 2) found characteristics such as altered foot positioning during gait, decreased dynamic postural stability and talar radiographic changes in patients with recurrent LAS. In a cross-sectional analysis by Hiller et al[82], 29\% of the general population reported a history of LAS, and $28 \%$ reported chronic ankle issues (pain, weakness, swelling, or instability), of which 52\% reported duration greater than 10 years.

There may be a host of functional and sensorimotor deficits that persist in the months following LAS.[83 84] Patients with LAS exhibit deficits in balance and movement coordination in the weeks and months following acute injury.[85-88] Doherty et al[89-96] following patients for up to 12 months following a first time acute LAS, observed a host of aberrant movement patterns that differed from individuals without a LAS. They concluded from 
8
1 their collective work that the LAS injury creates sensorimotor deficits that have not resolved in

2 spite of the patients returning to activity, which may have implications for re-injury.

3 Recurrent injury

LASs have the highest recurrence rates of all lower limb musculoskeletal injuries,[18 97-

599 ] with a two-fold increased risk of re-injury in the year following injury occurrence.[36 100]

6 However, it should be noted that a number of studies describing LAS recurrence rates are biased,

7 failing to control for details such as player function and/or position, which can influence injury

8 risk in some sports. Volleyball is a good example, where attacking players have a higher LAS

$9 \quad$ risk than other players.[36 101]

It is suggested that neuromuscular functioning is altered after an initial LAS due to damage of the ankle ligament receptors.[102] Resulting functional deficits include limited postural control, decreased maximal strength of the evertor muscles and prolonged muscle reaction time.[83 103] Even after successful return to play, ongoing deficits in neuromuscular control may contribute to a higher risk of a recurrent injury.[104] For example, individuals with a history of ankle sprain have greater fatigue-induced alterations of dynamic postural control.[105 106] It may be that further damaging of the already impaired ankle function after LAS recurrences is a significant contributor to CAI.

\section{From Lateral Ankle Sprain to Chronic Ankle Instability}

Many patients have ongoing pain, giving way and a feelings of instability in their ankle,[63] leading to persistent disability, which are characteristic features of CAI.[4] Hertel[107] proposed a model of CAI that denoted the occurrence of repetitive bouts of lateral ankle instability, resulting in numerous ankle sprains. His model integrated previous concepts of 1) mechanical instability (pathologic laxity after ankle-ligament injury)[108] and/or 2) functional 
1 instability (occurrence of recurrent ankle instability and the sensation of joint instability due to

2 the contributions of proprioceptive and neuromuscular deficits)[109 110]. Delahunt et al[4]

3 expanded the inclusion criteria that define insufficiencies in CAI as an encompassing term used

4 to classify a person with both mechanical and functional instability of the ankle joint. They

5 specified that in order to be categorized as having CAI, residual symptoms (" giving way" and

6 feelings of ankle joint instability) should be present for a minimum of one year post-initial 7 sprain.

The Hertel model[107] was revised by Hiller et al[111] in an effort to explain the inconsistencies in CAI research that were associated with the misconception that CAI is a homogeneous condition. These authors proposed that CAI should be considered as a heterogeneous condition including several homogeneous subgroups. Subsequently, the new model included seven subgroups integrating the concept of perceived instability instead of functional instability. This emerged from the development of questionnaires quantifying functional instability through the assessment of perceived instability,[112 113] with the intent to differentiate functional limitations that may coexist with other impairments in CAI patients. More recently, the Executive Committee of the International Ankle Consortium published a position statement regarding selection criteria for patients with CAI in controlled research focused on defining the acute LAS history and the functional limitations since injury through self-reported giving way episodes and validated patient reported outcome tools.[5-7]

\section{Prevalence of CAI}

There is a concerning trend in the literature for the prevalence of CAI. CAI develops in up to $70 \%$ of patients with a history of LAS,[17 8298$]$ and typically within a short period of time.[78 91-93 96] In a recent systematic review of the prevalence of CAI in sporting 
1 populations, Attenborough et al[114] indicated that CAI is a highly prevalent condition ( $>25 \%)$

2 in sports such as handball, basketball, soccer, and volleyball. This has been confirmed in more

3 recent investigations of collegiate and high school athletes in which the prevalence of CAI was

4 approximately $25 \%$ in those athletes with a previous history of injury.[115 116] Within the

5 performing arts population, such as ballet, over $50 \%$ of the dancers with a history of ankle sprain

6 report CAI.[117] This CAI prevalence trend extends out to the general population in which over

$720 \%$ of the general population with ankle injury reported having chronic issues.[82] Within that

8 study, chronicity following ankle sprain was most commonly associated with sporting activity.

9 While the development of CAI has been linked to the severity of LAS,[118] it may be

that our current societal awareness of CAI prevalence and its consequences on physical activity are poorly appreciated.[119 120] There is evidence to suggest that regardless of a first time or recurrent LAS, athletes are more likely to be returned to activity within 1 week of the injury.[75] When combining this evidence with the current prevalence trends in the literature, it is apparent that CAI is a persistent, if not a recalcitrant condition that is underappreciated and underestimated with regard to its public health burden.

\section{Theories for CAI Development}

While the prevalence and characteristics of CAI are well established, the causes for CAI development have not been established definitively. One hypothesis surrounds the culture of LAS being an innocuous injury. Thus many individuals do not seek initial care from any type of practitioner, preferring a "it will be fine" approach, perhaps with an application of ice and a brief period of rest. In fact, it has been reported that over half of sport players who sprained an ankle did not seek any type of care.[43 121] A secondary analysis from the work by Hiller et al[82] found a similar distribution where half of the people in a sample of the general population with 
1 an ankle sprain $(n=136 / 219)$, did not seek formal medical care. It may be that lack of medical

2 assessment and appropriate care is more likely to lead to the development of CAI, but due to the

3 difficulty of recruiting this population, there is no definitive evidence to support this hypothesis.

A second theory that may contribute to CAI development relates to the standard of care

5 administered for LAS, which may be too passive or too aggressive. The management of LAS in

6 many EDs is limited to advice on controlling acute inflammatory symptoms and restoration of

7 joint range of motion.[24 61 122] Discharge criteria are often vague and clinicians will routinely

8 avoid prognostication relating to recovery; and, typically there is inadequate follow-up care to

9 ensure restoration of function.[23 6388 123] This means that many patients with a LAS are susceptible to inadequate restoration of disease oriented outcomes of ROM, arthrokinematics, strength, balance and neuromuscular control.[124] While this has not been supported directly in 
1 may be too accelerated. A paradigm by Delahunt et al[125] proposes a "road map" to help

2 determine LAS patient needs and deficits that can shape clinical care decisions. Using these and

3 other potential approaches, prospective, randomized control trials are needed to determine

4 optimal dosage of initial management and rehabilitation for a return to activity timeline that 5 minimizes lingering instability and re-injury for LAS patients. These should also include long-

6 term follow-up assessments to determine successful patient outcomes.

7 A third theory for CAI development involves aberrant sensorimotor and neuromuscular 8 patterns that are observed in this population. Numerous retrospective studies have documented 9 alterations in balance, gait, and movement patterns in CAI patients that persist throughout the

lower extremity.[55 81 83-86 104-106 118 126-152] These documented deficits have expanded on the original theory by Freeman et al[109] that ankle ligamentous injury created a "deafferentation" whereby balance deficits would persist after LAS. Additionally, a collection of work has suggested there are adaptations within the central nervous system that may explain some of these observed sensorimotor changes in CAI patients.[149 153-162]

However, those observed patterns have been generated from retrospective study designs, limiting the conclusions that a LAS definitely creates these deficits in the CAI population.

Doherty et al[89-96 163-168] have conducted a large longitudinal prospective study to examine the onset of sensorimotor deficits following a LAS. In that series of papers, LAS patients were assessed at the time of their acute injury, as well as at 6-month and 12-month follow-ups. This collective work has demonstrated that postural control and multiple aberrant movement patterns during a variety of functional tasks are present and persist compared to non-injured cohorts. Additionally, these neuromuscular alterations appear in conjunction with patient reported disability and instability, suggesting that the foundation for CAI may begin to develop shortly 
1 after the acute LAS is incurred. Couple this with a potential lack of adequate care for LAS as we 2 suggest above, and one can begin to understand how re-injury and CAI can easily develop.

4 developing CAI. While genetic factors have been implicated in lower limb soft tissue 5 injuries[169 170], to date there is only one study of genetic factors in LAS. Shang et al[171]

6 (2015) reported that Chinese soldiers with the ACTN3 RR genotype had fewer acute ankle

7 sprains than a control group of soldiers with the same ethnic background and similar lifestyles.

8 There was no relationship between genotype frequency and severity of sprain. This preliminary

9 work gives initial support to the hypothesis that genetics may be involved in the development of

10 CAI; however, continued work, including prospective studies, are needed to confirm these

11 relationships and what interventions might be needed.

A final potential theory for consideration is how genetic factors may play a role in

\section{$\underline{\text { Post-traumatic Osteoarthritis Development }}$}

Based on the above evidence, a clear link has been made between LAS and the development of CAI. While less well-known, ankle joint PTOA has also been linked to both acute LAS and CAI. Ankle joint OA, regardless of etiology, represents a significant physical burden to the individual as evidenced by an average SF-36 physical component score of $32 \pm$ 8.[172] This profound physical limitation was noted in patients who averaged 53 years of age and represents subjective physical limitations comparable to those reported by patients with endstage kidney disease, congestive heart failure, and cervical pain and radiculopathy.[172] Research has also outlined that patients with end stage ankle joint OA, as measured radiographically, tend to be younger than patients with other lower extremity joint degeneration (e.g. knee or hip OA) and appear to present with faster functional loss with progression to the 
1 final stages of ankle joint OA in 10-20 years.[47] Additionally, between $70-80 \%$ of all ankle

2 joint OA cases are post-traumatic in nature,[44 172-174] likely explaining the younger onset and 3 faster functional loss.

$4 \quad$ Ligamentous injury and instability play a substantial role in the development of ankle

5 joint PTOA. More specifically, LASs account for $13-21.7 \%$ of all ankle joint OA cases (i.e.

6 primary, secondary, PTOA) and up to $80 \%$ of ankle joint PTOA cases.[44 47 172-174] It is

7 important to note that roughly $50 \%$ of ankle joint PTOA patients with a history of ligamentous

8 injury reported only a single LAS while the remaining patients reported recurrent sprains and/or

9 instability.[44 172 174] The end stage ankle joint PTOA patients in these investigations were, 10 on average 51.5[174] and 58[44] years of age, with Valderabanno et al.[44] noting an age range

12 years for the development of ankle joint PTOA following a single severe LAS and 28 years following recurrent LASs. It is important to remember that the patients in these investigations were being treated for end stage OA, which likely inflates the projected latency period. Similarly, in a 20-year follow-up study Lofvenberg et al.[175] reported $13 \%$ of 49 ankles with CAI had radiographic evidence of OA, but also reported $8.7 \%$ PTOA in a group that had recently sustained a LAS. The duration of time since the "recent" LAS or if the injury was a first-time sprain was not reported. These studies document consistent rates of ankle joint PTOA development following LAS, but Canale and Belding[176] observed a much higher percentage of CAI patients (48\%) who had radiographic evidence of degenerative OA at an 11-year followup.

While the studies above discuss the findings of radiographic evidence of ankle joint degeneration in patients with diagnosed ankle joint PTOA, a large body of evidence 
1 demonstrates early degenerative changes, osteochondral lesions, and/or intra-articular

2 pathologies in a high percentage of LAS patients sooner after the initial inciting injury than

3 previously anticipated. For the chronically unstable ankle, the evidence is focused on patients

4 reporting for lateral ligament stabilization and arthroscopic procedures. One of the first empirical

5 reports observed that 26 of 30 patients (87\%) who had a history of recurrent LAS for at least 10

6 years had evidence of arthritic changes via arthroscopic evaluation.[177] It is important to note

7 that the chief complaint was chronic pain following a history of LAS and not CAI. Other reports

8 demonstrate that $21-95 \%$ of patients with CAI have degenerative changes upon arthroscopic

9 review.[48 49 178-187]

On the low end of the range reported in the literature, Sammarco and DiRaimondo[182

188 ] noted only $21 \%$ of CAI patients had degenerative changes of any kind in the ankle joint at the time of a lateral ligament stabilization procedure. Hintermann et al.[178] found cartilage lesions in $55 \%$ of CAI patients via arthroscopic evaluation performed on average less than 2 years after the initial LAS. Similarly, Takao et al.[184] noted that $50 \%$ of his 72 patients (average age: 29 years) had degenerative changes but only $29 \%$ had osteochondral lesions. The mean time from injury to arthroscopic evaluation was only 7 months. On the other end of spectrum, Taga et al.[49] illustrated that $95 \%$ of chronically unstable ankles examined arthroscopically had chondral lesions, with an average age of only 20 years. Komenda[181] and Ferkel \& Chams[179] noted that $91 \%$ of patients with an unstable ankle had degenerative changes at the ankle joint, but only $25 \%$ of the patients (mean age: 31 years) had chondral lesions. Ferkel \& Chams[179] also found intra-articular problems in 95\% of CAI patients, with a mean age 28 years. The mean time from initial injury was just over 2 years. 
As stated earlier, the above data are all from patients needing a surgical procedure to treat 2 their CAI associated symptoms. Thus, it is possible that the percentages of reported ankle joint 3 OA, which have mostly included "symptomatic" patients seeking medical attention, could be 4 higher than in individuals who sustain recurrent episodes of giving way and recurrent LAS but 5 who do not feel the need to seek out medical care. However, it is difficult to determine if these 6 individuals that at present are not seeking medical attention would also have degenerative 7 changes given the lack of cartilage imaging performed for LAS and CAI. To date, few studies 8 have considered the interaction of symptoms with documented degenerative changes. Van 9 Ochten et al[186] reported that $40-55 \%$ of LAS patients in general practice with an average of 37 10 years had Kellgren and Lawrence scores of $>1$ within the talocrural and talonavicular compartments, regardless of presenting with persistent instability and functional limitations. In a 12 companion paper, the contralateral limb of a subset of those same unilateral LAS patients $(n=195)$ were scanned, with significant evidence of radiographic changes only present in the self-reported dysfunction does not necessarily help identify early development of PTOA.[186 187]

Further, Golditz et al[50] noted that both young, physically active CAI participants and LAS "copers" (i.e. those whom had sprained their ankle but not developed symptoms of CAI) had higher T2 relaxation times relative to uninjured controls. Increased relaxation times indicate a loss of water content and collagen fiber integrity. Most importantly, these CAI and LAS coper participants were 24.5 and 25.3 years of age, respectively, and had their initial LAS within 5 years of their MRI. These findings strongly support ankle degeneration in a small timeframe relative to initial LAS. While these findings within "asymptomatic" (i.e. those not seeking 
1 medical care) participants are consistent with arthroscopic evaluations, additional research using

2 MRI to quantify early degenerative changes are needed. The illustration of rapid ankle joint

3 degeneration could be a precursor to diagnosis of end stage ankle joint OA, which from the work

4 by Valderrabono et al[47] may not develop for 25-30 years after sustaining the acute LAS.

5 These emerging relationships requires follow-up research to determine how early degeneration

6 and end stage ankle OA relate, and if there are any viable interventions for this timeline.

7 The underlying etiology of these degenerative changes/intra-articular problems has not

8 yet been established. Taga et al[49] reported that $89 \%$ of acutely sprained ankles had

9 osteochondral lesions in patients whose mean age was 19 years. The authors suggest that acute joint PTOA etiology would appear to support this hypothesis, as roughly half of PTOA patients reporting ligamentous injury only report a single injury event.[44 174] The degenerative changes noted in LAS copers also suggest that a single LAS is sufficient to cause degenerative changes.[50] Lee et al[52] examined a series of patients reporting for arthroscopic marrow stimulation surgery. This sample was then examined for a history of a single LAS (copers) or CAI. As all participants were required to have osteochondral lesions, this investigation provides additional evidence that a single LAS is sufficient to cause osteochondral lesions, with an average duration of symptoms among the groups of approximately 28 months.

If the initial LAS is an underlying cause of osteochondral lesions, recurrent LASs and episodes of giving way likely exacerbate the contact stress adaptations,[51] further advancing degenerative changes. While speculative, this would place a premium on restoring appropriate biomechanics and motor control following a LAS in order to mitigate cartilage degeneration. Supporting this hypothesis, Golditz et al[189] found that mediolateral time to stabilization, a 
1 measure of dynamic postural stability recorded while landing from a jump, was correlated to the 2 increased relaxation times (i.e. worse cartilage health) in both "asymptomatic" CAI participants 3 and LAS copers. This suggests that ankle OA, even if asymptomatic, may be associated with

4 functional deficits; and if allowed to persist, could amplify and perhaps accelerate expected

5 limitations in activity levels as ankle joint health begins to deteriorate. This is clearly speculative

6 as no study to date has determined the effectiveness of any conservative or surgical interventions 7 for LAS or CAI at mitigating cartilage degeneration.

\section{Impact on Physical Activity, Quality of Life, and Co-Morbidity Risk}

Throughout this paper, the prevalence, financial impact, and high rate of ankle sprain reinjury and lingering instability illustrate the impact of this musculoskeletal injury. However, the contributions of musculoskeletal disease on health care and societal concerns extend beyond those factors. Specifically, patients with CAI present with decreases in quality of life[79 190194] and physical activity,[78 119120195 196] as well as accelerated onset of ankle joint OA,[44 45484951197198 ] oftentimes as early as the $3^{\text {rd }}$ decade of life.[50] These factors all contribute to a paradigm of compromised health and wellness, which are established correlates with co-morbidity risk. Therefore, we must consider that the links to health-related consequences and the broader impact of ankle instability are becoming more tangible.

\section{Physical Activity Related Consequences}

The importance of physical activity as a conduit to good physical and emotional health is well accepted. Injury is one factor that creates short-term and long-term interruption to physical activity. The abundance of LASs we have discussed earlier illustrates the immediate and shortterm disruptions in ADLs and recreational/sport physical activity. The pain and swelling that 
1 accompany acute ankle joint injury are difficult to ignore, and instill noticeable weight-bearing

2 challenges and alterations to gait and movement coordination, temporarily downgrading physical

3 activity. The general population perceives the threat to physical activity is removed once initial

4 pain is reduced and swelling subsides, and a complete recovery is attainable in a matter of

5 days.[75] At face value, this is true and achievable through therapeutic and pharmaceutical

6 interventions, and most patients with a LAS can return to ADLs, occupational activity and

7 recreational/sporting activities in a relatively short period of time.[75] However, what is not

8 appreciated in the general population, and perhaps in the medical community, is that LAS

9 patients, especially those that transition into CAI patients, are susceptible to lingering disruptions in physical activity throughout the lifespan.

Using animal models, the negative influence of acute and CAI on physical activity has been illustrated. Hubbard-Turner et al[199] induced acute ankle instability in mice by transecting lateral ankle ligaments, and then monitored self-selected physical activity during the first 4 weeks after injury, representing the acute phase of injury recovery. Injured mice groups spent less time on a running wheel with slower walking speeds than uninjured mice. In a companion study, the research group monitored the mice as they recovered from the induced injury. They observed that the injured mice developed CAI-like symptoms as evidenced by more foot slips ("giving way") during balance and gait activities.[195] Finally, this research group reported these "CAI" mice to have lower levels of activity levels using the running wheels throughout their lifespan compared to the uninjured mice, suggesting a negative influence of the ankle injury on lifelong physical activity.[120] This mouse model indicates that with LAS, physical activity declines immediately, and it is likely that the injured individuals will develop CAI, mimicking what has been discussed in human populations previously in this review. The work by this group 
1 also suggests that ankle injury triggers a lifelong decline in physical activity, which is an

2 important factor to consider in understanding the larger impact on health status.

The negative influence of ankle injury history on physical activity has also been

4 documented in human populations. During a seven-year follow-up to injury by Konradsen et $5 a l,[78] 72 \%$ of over 600 enrolled LAS patients self-reported remaining functionally impaired, 6 including inability to perform sports and physical activity, due to their ankle injury. The median 7 age was 29 years, and only a small percentage of patients still reported pain (16\%) and swelling 8 (22\%), suggesting that the lingering disruptions in functional ability years after injury were not 9 due to aging or chronic inflammation. In a survey of the general population, Hiller et al[82] observed that $55 \%$ of those with ankle sprain report limitations in physical activity that result in an inability to participate in tasks that could be performed before injury. Ankle sprains may also impact occupational activity and demands. Verhagen et al[196] from a 6.5 year follow-up of 577 patients with LAS, report that $15 \%$ had lingering "handicaps" to their occupational activities, while $6 \%$ were unable to maintain their occupational activities at all. These discussed studies encompass large cross-sectional population samples, challenging the notion that these disruptions to physical activity from ankle sprain are simply a product of aging. While none of these studies used age as a covariate to examine that question, it appears that the majority of the participants in these studies were young and middle-age adults. Hubbard-Turner and Turner[119] have shown that young adults with CAI engage in lower self-selected levels of physical activity compared to age-matched individuals with no history of ankle injury. Using pedometers, collegeaged students in their early twenties with CAI demonstrated significantly fewer weekly steps taken and minutes engaged in moderate to vigorous activity compared to a non-injured cohort. Collectively, this work indicates that a history of LAS associates with a decline in physical 
1 activity well after symptoms of the acute injury subside, but this decline is not necessarily a

2 product of aging.

3 A consequence of physical activity decline is the likelihood of an increase in BMI. In a

4 large study of over 800,000 individuals, Herskovich et al[200] found that males and females who

5 were obese or overweight were more likely to have CAI (range of OR: 1.19-3.29) compared to

6 those with a healthy weight. However, this study did not quantify the level of physical activity

7 among the study participants. While the negative long-term impact of LAS on physical activity

8 and the potential effect on BMI is being established, a specific explanation for these negative

9 impacts has not been clearly articulated. As discussed in the previous sections, LASs are likely to

10 develop into CAI with the increasing number of documented cases of early onset of ankle joint

11 PTOA.[44 45 48-50] Associations with lingering ankle pain and instability that persist in CAI

12 populations should be considered when attempting to form links to the diminished levels of these and other factors will be important for development of effective strategies to overcome limitations to physical activity.

\section{Quality of Life Related Consequences}

Related to the limitations in physical activity, an additional consequence of injury is a likely decline in the patient's quality of life (QOL). Evidence is mounting that a LAS may initiate a degradation in QOL levels in patients long after they have recovered from the acute symptoms of the injury. Anandacoomarasamy and Barnsley[79], using the SF-36 general health subscale, found in a small cohort of 19 lateral ankle sprain patients a decrease in QOL over a two-year period compared to age matched controls. The majority (74\%) of these injured subjects 
1 still had lingering pain, swelling, and/or lingering instability at the two-year follow up. Using

2 the same assessment in a larger cohort of 68 individuals with a history of at least one ankle

3 sprain and ongoing instability, Arnold et al[190] found similar declines in QOL compared to

4 individuals without ankle sprain history. The authors of that study do not describe the amount of

5 time since suffering the acute lateral ankle sprains for their injured participants, but do designate

6 that the participants were free from any acute symptoms. This suggests that while there should

7 have been a substantial time for recovery from the injury, there was a significant decline in QOL.

Houston et al[191 193 194] also have considered the effect of ankle injury history on QOL, as well as what factors might help explain this decline. In a systematic review, this group concluded that patients with CAI demonstrated disability and deficits in function on ankle specific patient reported outcome measures, as well as generic health-related QOL outcome measures compared to non-injured and LAS coper populations.[194] In their own case control study, this group reported that individuals with CAI displayed decreased function using the Disablement in the Physically Active Scale, while simultaneously displaying increased levels of fear of injury using the Fear-Avoidance Beliefs Questionnaire and the Tampa Scale of Kinesiophobia.[191] Additionally, this group has demonstrated that the ankle specific disability measures can be explained with physical and functional clinical measures, such as balance, strength, or ROM.[193] This suggests that clinical and functional impairments that are addressed in rehabilitation may be able to reduce ankle specific disability, but there is a need for more comprehensive assessment of these patients during rehabilitation for LAS to address what factors may be creating long-term threats to QOL.

The work described by Houston et al[191 193 194] illustrates that the degradation in QOL occurs as LAS patients downgrade into CAI populations. Alarmingly, this is being 
1 observed in young adult patients under the age of 30. Simon and Docherty[201] report similar a

2 phenomenon, but in a broader age range of the population. Former Division I collegiate athletes

$3 \quad(n=232)$ who were between the ages of 40-60 years self-reported their current QOL using the

4 American Academy of Orthopaedic Surgeons Lower Limb Questionnaire and the Short Form -

5 36v2. Even with this older age range, individuals with CAI reported decreased function and

6 QOL compared with individuals without CAI. The largest differences were seen on the

7 American Academy of Orthopaedic Surgeons Lower Limb Questionnaire, as well as the Physical

8 Component Summary Score and physical function scales of the SF-36v2.[201]

9

\section{$\underline{\text { Section B Summary }}$}

It is important to contextualize the trend of CAI and the associated consequences as it translates to at least 1 out of every 5 people in the public who incur a LAS will go on to report chronic problems.[82] These trends are higher in athletic populations (at least 1 of 3)[114 116] and among dancers (1 out of 2)[117]. When examining the trends within the general public, individuals with chronic ankle problems report increased modification of functional activity and reduced overall health compared to their non-injured counterparts in the community. It is apparent that CAI is a highly prevalent condition, especially in those who are physically active. The lingering deficits in disease and patient-oriented outcome measures observed in CAI patients

are likely persisting beyond the LAS. More investigation is needed to determine the source of 22 these issues that lead to chronicity, from which more effective prevention and treatment 
1 strategies can be developed. If these are not addressed, these patients are likely to develop long-

2 term issues that may threaten physical activity and general health.

3 The evidence is growing that an important consequence of LAS, and the subsequent high

4 rate of CAI, is ankle joint PTOA, affecting a disproportionately young population group, and

5 subsequently increasing the number of disability-affected life years. Patients with a history of

6 LAS make up the majority of the surgical cases for end-stage ankle joint PTOA. Emerging

7 information is supporting that CAI represents an important period in the early stages of ankle

8 joint degeneration and may even be a key mediator driving the disease process. Continued work

9 in this area is needed to elucidate fully the paradigms between LAS, CAI and ankle joint PTOA.

The documentation of reductions in physical activity, increases in BMI, and declines in QOL from ankle sprain history in animal and human models is growing. It appears this paradigm of negative consequences from LAS is independent of age related declines in QOL, and manifests itself early after the initial injury when patients are still adolescents and/or young adults. The limited data we have show similar CAI related issues impact older adult populations as well, suggesting this injury and its consequence are more complex than initially understood, with persistence throughout the lifespan. Additionally, this is an issue not only impacting the competitive athlete, but is being reported throughout the general population. More epidemiological work, especially longitudinal studies, are needed to quantify the threats to general health as a means of defining the comprehensive health care burden from LAS. Because of the links of LAS and CAI to physical activity, BMI, QOL, and OA, it will be important to ascertain potential associations of ankle injury to other disease co-morbidities. This will emphasize the need for improved comprehensive treatment of acute LAS and CAI beyond the goal of returning to exercise and sport. 


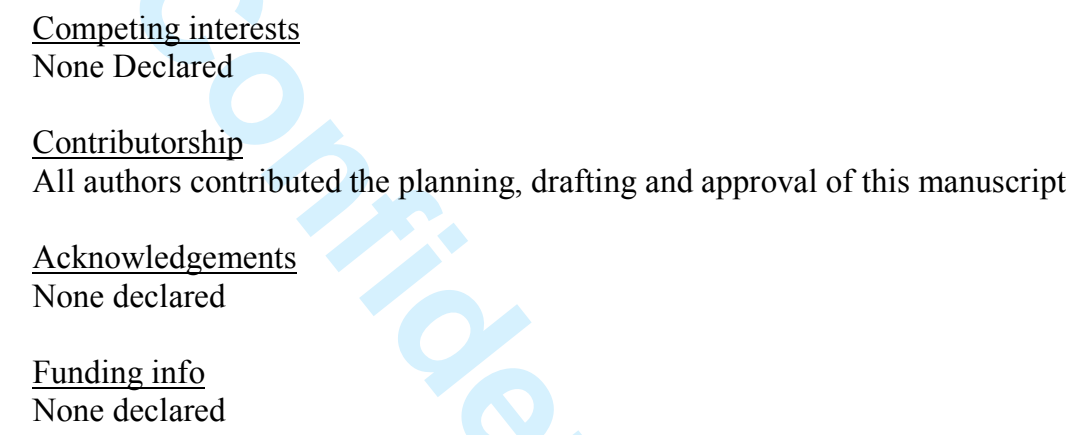




\section{References}

1. Finch C, Owen N, Price R. Current injury or disability as a barrier to being more physically active. Medicine and science in sports and exercise 2001;33(5):778-82

2. Telford A, Finch CF, Barnett L, Abbott G, Salmon J. Do parents' and children's concerns about sports safety and injury risk relate to how much physical activity children do? British journal of sports medicine 2012;46(15):1084-8 doi: 10.1136/bjsports-2011-090904[published Online First: Epub Date]|.

3. Waterman B, Owens B, Davey S, Zacchilli M, Belmont P. The epidemiology of ankle sprains in the United States. Journal of Bone and Joint Surgery. American Volume 2010;92(13):2279-84

4. Delahunt E, Coughlan GF, Caulfield B, Nightingale EJ, Lin CWC, Hiller CE. Inclusion Criteria When Investigating Insufficiencies in Chronic Ankle Instability. Medicine and science in sports and exercise 2010;42(11):2106-21 doi: 10.1249/MSS.0b013e3181de7a8a[published Online First: Epub Date]|.

5. Gribble PA, Delahunt E, Bleakley C, et al. Selection criteria for patients with chronic ankle instability in controlled research: a position statement of the International Ankle Consortium. British journal of sports medicine 2014;48(13):1014-8 doi: 10.1136/bjsports-2013-093175[published Online First: Epub Date]|.

6. Gribble PA, Delahunt E, Bleakley C, et al. Selection criteria for patients with chronic ankle instability in controlled research: a position statement of the International Ankle Consortium. The Journal of orthopaedic and sports physical therapy 2013;43(8):585-91 doi: 10.2519/jospt.2013.0303[published Online First: Epub Date]|.

7. Gribble PA, Delahunt E, Bleakley CM, et al. Selection criteria for patients with chronic ankle instability in controlled research: a position statement of the International Ankle Consortium. Journal of athletic training 2014;49(1):121-7 doi: 10.4085/1062-6050-49.1.14[published Online First: Epub Date]|.

8. Doherty C, Delahunt E, Caulfield B, Hertel J, Ryan J, Bleakley C. The incidence and prevalence of ankle sprain injury: a systematic review and meta-analysis of prospective epidemiological studies. Sports medicine (Auckland, N.Z.) 2014;44(1):123-40 doi: 10.1007/s40279-013-0102-5[published Online First: Epub Date]|.

9. Andersen TE, Floerenes TW, Arnason A, Bahr R. Video analysis of the mechanisms for ankle injuries in football. The American journal of sports medicine 2004;32(1 Suppl):69s-79s

10. Fong DT, Hong Y, Shima Y, Krosshaug T, Yung PS, Chan KM. Biomechanics of supination ankle sprain: a case report of an accidental injury event in the laboratory. The American journal of sports medicine 2009;37(4):822-7 doi: 10.1177/0363546508328102[published Online First: Epub Date]|.

11. Gehring D, Wissler S, Mornieux G, Gollhofer A. How to sprain your ankle - a biomechanical case report of an inversion trauma. Journal of biomechanics 2013;46(1):175-8 doi: 10.1016/j.jbiomech.2012.09.016[published Online First: Epub Date]|.

12. Kristianslund $E$, Bahr R, Krosshaug $T$. Kinematics and kinetics of an accidental lateral ankle sprain. Journal of biomechanics 2011;44(14):2576-8 doi: 10.1016/j.jbiomech.2011.07.014[published Online First: Epub Date]|.

13. Terada M, Gribble PA. Jump Landing Biomechanics During a Laboratory Recorded Recurrent Ankle Sprain. Foot \& ankle international 2015;36(7):842-8 doi: 10.1177/1071100715576517[published Online First: Epub Date]|.

14. Mok KM, Fong DT, Krosshaug $\mathrm{T}$, et al. Kinematics analysis of ankle inversion ligamentous sprain injuries in sports: 2 cases during the 2008 Beijing Olympics. The American journal of sports 
medicine 2011;39(7):1548-52 doi: 10.1177/0363546511399384[published Online First: Epub Date]|.

15. Fong DT, Ha SC, Mok KM, Chan CW, Chan KM. Kinematics analysis of ankle inversion ligamentous sprain injuries in sports: five cases from televised tennis competitions. The American journal of sports medicine 2012;40(11):2627-32 doi: 10.1177/0363546512458259[published Online First: Epub Date]|.

16. Tropp H. Commentary: Functional Ankle Instability Revisited. Journal of athletic training 2002;37(4):512-15

17. Fong DTP, Hong YL, Chan LK, Yung PSH, Chan KM. A systematic review on ankle injury and ankle sprain in sports. Sports Medicine 2007;37(1):73-94 doi: 10.2165/00007256-20073701000006[published Online First: Epub Date]|.

18. Hootman J, Dick R, Agel J. Epidemiology of collegiate injuries for 15 sports: summary and recommendations for injury prevention initiatives. Journal of athletic training 2007;42(2):311-19

19. FIFA. Secondary FIFA. http://www.fifa.com/worldfootball/bigcount/

20. FIBA: worldwide basketball player numbers. Secondary FIBA: worldwide basketball player numbers. http://www.fiba.com/pages/eng/fc/FIBA/quicFact/p/openNodelDs/962/selNodelD/962/quicFac ts.html.

21. Cameron KL, Owens BD, DeBerardino TM. Incidence of ankle sprains among active-duty members of the United States Armed Services from 1998 through 2006. Journal of athletic training 2010;45(1):29-38 doi: 10.4085/1062-6050-45.1.29[published Online First: Epub Date]|.

22. Bulathsinhala L, Hill OT, Scofield DE, Haley TF, Kardouni JR. Epidemiology of Ankle Sprains and the Risk of Separation From Service in U.S. Army Soldiers. The Journal of orthopaedic and sports physical therapy 2015;45(6):477-84 doi: 10.2519/jospt.2015.5733[published Online First: Epub Date]|.

23. Cooke M, Lamb S, Marsh J, Dale J. A survey of current consultant practice of treatment of severe ankle sprains in emergency departments in the United Kingdom. Emergeny Medicine Journal 2003;20(6):505-07

24. Lamb SE, Marsh JL, Hutton JL, Nakash R, Cooke MW. Mechanical supports for acute, severe ankle sprain: a pragmatic, multicentre, randomised controlled trial. Lancet 2009;373(9663):575-81 doi: 10.1016/s0140-6736(09)60206-3[published Online First: Epub Date]|.

25. Holmer P, Sondergaard L, Konradsen L, Nielsen PT, Jorgensen LN. Epidemiology of sprains in the lateral ankle and foot. Foot \& ankle international 1994;15(2):72-4

26. Bridgman SA, Clement D, Downing A, Walley G, Phair I, Maffulli N. Population based epidemiology of ankle sprains attending accident and emergency units in the West Midlands of England, and a survey of UK practice for severe ankle sprains. Emergency medicine journal : EMJ 2003;20(6):508-10

27. Lambers K, Ootes D, Ring D. Incidence of patients with lower extremity injuries presenting to US emergency departments by anatomic region, disease category, and age. Clinical orthopaedics and related research 2012;470(1):284-90 doi: 10.1007/s11999-011-1982-z[published Online First: Epub Date]|.

28. Kemler E, van de Port I, Valkenberg H, Hoes AW, Backx FJ. Ankle injuries in the Netherlands: Trends over 10-25 years. Scandinavian journal of medicine \& science in sports 2015;25(3):331-7 doi: 10.1111/sms.12248[published Online First: Epub Date]|.

29. Anis AH, Stiell IG, Stewart DG, Laupacis A. Cost-effectiveness analysis of the Ottawa Ankle Rules. Annals of emergency medicine 1995;26(4):422-8

30. Derksen RJ, Coupe VM, van Tulder MW, Veenings B, Bakker FC. Cost-effectiveness of the SENconcept: Specialized Emergency Nurses (SEN) treating ankle/foot injuries. BMC musculoskeletal disorders 2007;8:99 doi: 10.1186/1471-2474-8-99[published Online First: Epub Date]|. 


\section{Hupperets MD, Verhagen EA, Heymans MW, Bosmans JE, van Tulder MW, van Mechelen W.} Potential savings of a program to prevent ankle sprain recurrence: economic evaluation of a randomized controlled trial. The American journal of sports medicine 2010;38(11):2194-200 doi: 10.1177/0363546510373470[published Online First: Epub Date]|.

32. Janssen KW, Hendriks MR, van Mechelen W, Verhagen E. The Cost-Effectiveness of Measures to Prevent Recurrent Ankle Sprains: Results of a 3-Arm Randomized Controlled Trial. The American journal of sports medicine 2014;42(7):1534-41 doi: 10.1177/0363546514529642[published Online First: Epub Date]|.

33. Lin CW, Uegaki K, Coupe VM, Kerkhoffs GM, van Tulder MW. Economic evaluations of diagnostic tests, treatment and prevention for lateral ankle sprains: a systematic review. British journal of sports medicine 2013;47(18):1144-9 doi: 10.1136/bjsports-2012-090319[published Online First: Epub Date]|.

34. Olmsted LC, Vela LI, Denegar CR, Hertel J. Prophylactic Ankle Taping and Bracing: A NumbersNeeded-to-Treat and Cost-Benefit Analysis. Journal of athletic training 2004;39(1):95-100

35. Ramasubbu B, McNamara R, Okafor I, Deiratany S. Evaluation of Safety and Cost-Effectiveness of the Low Risk Ankle Rule in One of Europe's Busiest Pediatric Emergency Departments. Pediatric emergency care 2015;31(10):685-7 doi: 10.1097/pec.0000000000000474[published Online First: Epub Date]|.

36. Verhagen EA, van Tulder M, van der Beek AJ, Bouter LM, van Mechelen W. An economic evaluation of a proprioceptive balance board training programme for the prevention of ankle sprains in volleyball. British journal of sports medicine 2005;39(2):111-5 doi: 10.1136/bjsm.2003.011031[published Online First: Epub Date]|.

37. Drummond M, Sculpher G, Thorrance M, OBrien G, Stoddart B. Methods for the Economic Evaluation of Health Care Programmes. 3rd ed. New York: Oxford University Press, 2013.

38. Bosmans J, Heymans M, Hupperets M, van Tulder M. Cost-effectiveness studies. In: Verhagen E, Van Mechelen W, eds. Sports Injury Research. Oxford: Oxford University Press, 2010:195-210.

39. Knowles SB, Marshall SW, Miller T, et al. Cost of injuries from a prospective cohort study of North Carolina high school athletes. Injury prevention : journal of the International Society for Child and Adolescent Injury Prevention 2007;13(6):416-21 doi: 10.1136/ip.2006.014720[published Online First: Epub Date]|.

40. Cooke MW, Marsh JL, Clark M, et al. Treatment of severe ankle sprain: a pragmatic randomised controlled trial comparing the clinical effectiveness and cost-effectiveness of three types of mechanical ankle support with tubular bandage. The CAST trial. Health technology assessment (Winchester, England) 2009;13(13):iii, ix-x, 1-121 doi: 10.3310/hta13130[published Online First: Epub Date]|.

41. De Boer AS, Schepers T, Panneman MJ, Van Beeck EF, Van Lieshout EM. Health care consumption and costs due to foot and ankle injuries in the Netherlands, 1986-2010. BMC musculoskeletal disorders 2014;15:128 doi: 10.1186/1471-2474-15-128[published Online First: Epub Date]|.

42. Consument en Veiligheid. Cijfers over sportblessures. Secondary Consument en Veiligheid. Cijfers over sportblessures. https://www.veiligheid.nl/sportblessures/kennis/cijfers-oversportblessures.

43. McKay G, Goldie P, Payne W, Oakes B. Ankle injuries in basketball: injury rate and risk factors. British journal of sports medicine 2001;35(2):103-8

44. Valderrabano V, Horisberger M, Russell I, Dougall H, Hintermann B. Etiology of ankle osteoarthritis. Clinical orthopaedics and related research 2009;467(7):1800-6 doi: 10.1007/s11999-008-05436[published Online First: Epub Date]|.

45. Valderrabano V, Pagenstert G, Horisberger M, Knupp M, Hintermann B. Sports and recreation activity of ankle arthritis patients before and after total ankle replacement. The American 
journal of sports medicine 2006;34(6):993-9 doi: 10.1177/0363546505284189[published Online First: Epub Date]|.

46. Nieuwe Weme RA, van Solinge G, J ND, Sierevelt I, Haverkamp D, Doets HC. Total ankle replacement for posttraumatic arthritis. Similar outcome in postfracture and instability arthritis: a comparison of 90 ankles. Acta orthopaedica 2015;86(4):401-6 doi: 10.3109/17453674.2015.1029842[published Online First: Epub Date]|.

47. Valderrabano V, Hintermann B, Horisberger M, Fung TS. Ligamentous posttraumatic ankle osteoarthritis. The American journal of sports medicine 2006;34(4):612-20 doi: 10.1177/0363546505281813[published Online First: Epub Date]|.

48. Hirose K, Murakami G, Minowa T, Kura H, Yamashita T. Lateral ligament injury of the ankle and associated articular cartilage degeneration in the talocrural joint: anatomic study using elderly cadavers. Journal of orthopaedic science : official journal of the Japanese Orthopaedic Association 2004;9(1):37-43 doi: 10.1007/s00776-003-0732-9[published Online First: Epub Date]|.

49. Taga I, Shino K, Inoue M, Nakata K, Maeda A. Articular cartilage lesions in ankles with lateral ligament injury. An arthroscopic study. The American journal of sports medicine 1993;21(1):1206; discussion 26-7

50. Golditz T, Steib S, Pfeifer K, et al. Functional ankle instability as a risk factor for osteoarthritis: using T2-mapping to analyze early cartilage degeneration in the ankle joint of young athletes. Osteoarthritis and cartilage / OARS, Osteoarthritis Research Society 2014;22(10):1377-85 doi: 10.1016/j.joca.2014.04.029[published Online First: Epub Date]|.

51. Bischof JE, Spritzer CE, Caputo AM, et al. In vivo cartilage contact strains in patients with lateral ankle instability. Journal of biomechanics 2010;43(13):2561-6 doi: 10.1016/j.jbiomech.2010.05.013[published Online First: Epub Date]|.

52. Lee M, Kwon JW, Choi WJ, Lee JW. Comparison of Outcomes for Osteochondral Lesions of the Talus With and Without Chronic Lateral Ankle Instability. Foot \& ankle international 2015;36(9):10507 doi: 10.1177/1071100715581477[published Online First: Epub Date]|.

53. Cain MS, Garceau SW, Linens SW. Effects of a Four Week Biomechanical Ankle Platform System Protocol on Balance in High School Athletes with Chronic Ankle Instability. Journal of sport rehabilitation 2015 doi: 10-1123/jsr.2015-0045[published Online First: Epub Date]|.

54. De Ridder R, Willems TM, Vanrenterghem J, Roosen P. Effect of a Home-based Balance Training Protocol on Dynamic Postural Control in Subjects with Chronic Ankle Instability. International journal of sports medicine 2015;36(7):596-602 doi: 10.1055/s-0034-1396823[published Online First: Epub Date]|.

55. Donovan L, Hertel J. A new paradigm for rehabilitation of patients with chronic ankle instability. The Physician and sportsmedicine 2012;40(4):41-51 doi: 10.3810/psm.2012.11.1987[published Online First: Epub Date]|.

56. Hale SA, Fergus A, Axmacher R, Kiser K. Bilateral improvements in lower extremity function after unilateral balance training in individuals with chronic ankle instability. Journal of athletic training 2014;49(2):181-91 doi: 10.4085/1062-6050-49.2.06[published Online First: Epub Date]|.

57. Hale SA, Hertel J, Olmsted-Kramer LC. The effect of a 4-week comprehensive rehabilitation program on postural control and lower extremity function in individuals with chronic ankle instability. The Journal of orthopaedic and sports physical therapy 2007;37(6):303-11 doi: 10.2519/jospt.2007.2322[published Online First: Epub Date]|.

58. Hall EA, Docherty CL, Simon J, Kingma JJ, Klossner JC. Strength-training protocols to improve deficits in participants with chronic ankle instability: a randomized controlled trial. Journal of athletic training 2015;50(1):36-44 doi: 10.4085/1062-6050-49.3.71[published Online First: Epub Date]|. 
59. Holmes A, Delahunt E. Treatment of common deficits associated with chronic ankle instability. Sports medicine (Auckland, N.Z.) 2009;39(3):207-24 doi: 10.2165/00007256-20093903000003[published Online First: Epub Date]|.

60. Linens SW, Ross SE, Arnold BL. Wobble Board Rehabilitation for Improving Balance in Ankles With Chronic Instability. Clinical journal of sport medicine : official journal of the Canadian Academy of Sport Medicine 2015 doi: 10.1097/jsm.0000000000000191[published Online First: Epub Date]l.

61. McCriskin BJ, Cameron KL, Orr JD, Waterman BR. Management and prevention of acute and chronic lateral ankle instability in athletic patient populations. World journal of orthopedics 2015;6(2):161-71 doi: 10.5312/wjo.v6.i2.161[published Online First: Epub Date]|.

62. O'Driscoll J, Delahunt E. Neuromuscular training to enhance sensorimotor and functional deficits in subjects with chronic ankle instability: A systematic review and best evidence synthesis. Sports medicine, arthroscopy, rehabilitation, therapy \& technology : SMARTT 2011;3:19 doi: 10.1186/1758-2555-3-19[published Online First: Epub Date]|.

63. van Ochten JM, van Middelkoop M, Meuffels D, Bierma-Zeinstra SM. Chronic complaints after ankle sprains: a systematic review on effectiveness of treatments. The Journal of orthopaedic and sports physical therapy 2014;44(11):862-71, c1-23 doi: 10.2519/jospt.2014.5221[published Online First: Epub Date]|.

64. Webster KA, Gribble PA. Functional rehabilitation interventions for chronic ankle instability: a systematic review. Journal of sport rehabilitation 2010;19(1):98-114

65. Wortmann MA, Docherty CL. Effect of balance training on postural stability in subjects with chronic ankle instability. Journal of sport rehabilitation 2013;22(2):143-9

66. Cho BK, Kim YM, Park KJ, Park JK, Kim DK. A prospective outcome and cost-effectiveness comparison between two ligament reattachment techniques using suture anchors for chronic ankle instability. Foot \& ankle international 2015;36(2):172-9 doi: 10.1177/1071100714552079[published Online First: Epub Date]|.

67. Hsu AR, Ardoin GT, Davis WH, Anderson RB. Intermediate and Long-Term Outcomes of the Modified Brostrom-Evans Procedure for Lateral Ankle Ligament Reconstruction. Foot \& ankle specialist 2015 doi: 10.1177/1938640015609970[published Online First: Epub Date]|.

68. Girard P, Anderson RB, Davis WH, Isear JA, Kiebzak GM. Clinical evaluation of the modified BrostromEvans procedure to restore ankle stability. Foot \& ankle international 1999;20(4):246-52

69. Petrera M, Dwyer T, Theodoropoulos JS, Ogilvie-Harris DJ. Short- to Medium-term Outcomes After a Modified Brostrom Repair for Lateral Ankle Instability With Immediate Postoperative Weightbearing. The American journal of sports medicine 2014;42(7):1542-8 doi: 10.1177/0363546514530668[published Online First: Epub Date]|.

70. Nery C, Raduan F, Del Buono A, Asaumi ID, Cohen M, Maffulli N. Arthroscopic-assisted BrostromGould for chronic ankle instability: a long-term follow-up. The American journal of sports medicine 2011;39(11):2381-8 doi: 10.1177/0363546511416069[published Online First: Epub Date]|.

71. Nwachukwu BU, McLawhorn AS, Simon MS, et al. Management of End-Stage Ankle Arthritis: CostUtility Analysis Using Direct and Indirect Costs. The Journal of bone and joint surgery. American volume 2015;97(14):1159-72 doi: 10.2106/jbjs.n.01215[published Online First: Epub Date]|.

72. Bleakley CM, McDonough SM, MacAuley DC. Some conservative strategies are effective when added to controlled mobilisation with external support after acute ankle sprain: a systematic review. The Australian journal of physiotherapy 2008;54(1):7-20

73. Bleakley CM, McDonough SM, MacAuley DC, Bjordal J. Cryotherapy for acute ankle sprains: a randomised controlled study of two different icing protocols. British journal of sports medicine 
2006;40(8):700-5; discussion 05 doi: 10.1136/bjsm.2006.025932[published Online First: Epub Date]|.

74. Petersen W, Rembitzki IV, Koppenburg AG, et al. Treatment of acute ankle ligament injuries: a systematic review. Archives of orthopaedic and trauma surgery 2013;133(8):1129-41 doi: 10.1007/s00402-013-1742-5[published Online First: Epub Date]|.

75. Medina McKeon JM, Bush HM, Reed A, Whittington A, Uhl TL, McKeon PO. Return-to-play probabilities following new versus recurrent ankle sprains in high school athletes. Journal of science and medicine in sport / Sports Medicine Australia 2014;17(1):23-8 doi: 10.1016/j.jsams.2013.04.006[published Online First: Epub Date]|.

76. van Rijn RM, van Os AG, Bernsen RM, Luijsterburg PA, Koes BW, Bierma-Zeinstra SM. What is the clinical course of acute ankle sprains? A systematic literature review. The American journal of medicine 2008;121(4):324-31.e6 doi: 10.1016/j.amjmed.2007.11.018[published Online First: Epub Date]|.

77. Gerber JP, Williams GN, Scoville CR, Arciero RA, Taylor DC. Persistent disability associated with ankle sprains: a prospective examination of an athletic population. Foot \& ankle international 1998;19(10):653-60

78. Konradsen $\mathrm{L}$, Bech $\mathrm{L}$, Ehrenbjerg M, Nickelsen T. Seven years follow-up after ankle inversion trauma. Scandinavian journal of medicine \& science in sports 2002;12(3):129-35 doi: 10.1034/j.16000838.2002.02104.x[published Online First: Epub Date]|.

79. Anandacoomarasamy A, Barnsley L. Long term outcomes of inversion ankle injuries. British journal of sports medicine 2005;39(3) doi: e14

10.1136/bjsm.2004.011676[published Online First: Epub Date]|.

80. Braun BL. Effects of ankle sprain in a general clinic population 6 to 18 months after medical evaluation. Archives of family medicine 1999;8(2):143-8

81. Hiller CE, Ightingale EJN, Lin CWC, Coughlan GF, Caulfield B, Delahunt E. Characteristics of people with recurrent ankle sprains: a systematic review with meta-analysis. British journal of sports medicine 2011;45(8):660-72 doi: 10.1136/bjsm.2010.077404[published Online First: Epub Date]|.

82. Hiller CE, Nightingale EJ, Raymond J, et al. Prevalence and Impact of Chronic Musculoskeletal Ankle Disorders in the Community. Archives of physical medicine and rehabilitation 2012;93(10):180107 doi: 10.1016/j.apmr.2012.04.023[published Online First: Epub Date]|.

83. Hertel J. Sensorimotor deficits with ankle sprains and chronic ankle instability. Clinics in sports medicine 2008;27:353-70

84. McKeon P, Hertel J. Systematic review of postural control and lateral ankle instability, part I: can deficits be detected with instrumented testing. Journal of athletic training 2008;43(3):293-304

85. Bastien M, Moffet H, Bouyer L, Perron M, Hebert L, Leblond J. Alteration in global motor strategy following lateral ankle sprain. BMC musculoskeletal disorders 2014;15:436 doi: 10.1186/14712474-15-436[published Online First: Epub Date]|.

86. Wikstrom EA, Naik S, Lodha N, Cauraugh JH. Bilateral balance impairments after lateral ankle trauma: a systematic review and meta-analysis. Gait \& posture 2010;31(4):407-14 doi: 10.1016/j.gaitpost.2010.02.004[published Online First: Epub Date]|.

87. Goldie PA, Evans OM, Bach TM. Postural control following inversion injuries of the ankle. Archives of physical medicine and rehabilitation 1994;75(9):969-75

88. Punt IM, Ziltener JL, Laidet M, Armand S, Allet L. Gait and physical impairments in patients with acute ankle sprains who did not receive physical therapy. PM \& $R$ : the journal of injury, function, and rehabilitation 2015;7(1):34-41 doi: 10.1016/j.pmrj.2014.06.014[published Online First: Epub Date]|. 
89. Doherty C, Bleakley C, Hertel J, Caulfield B, Ryan J, Delahunt E. Single-leg drop landing movement strategies 6 months following first-time acute lateral ankle sprain injury. Scandinavian journal of medicine \& science in sports 2015;25(6):806-17 doi: 10.1111/sms.12390[published Online First: Epub Date]|.

90. Doherty C, Bleakley C, Hertel J, Caulfield B, Ryan J, Delahunt E. Dynamic Balance Deficits 6 Months Following First-Time Acute Lateral Ankle Sprain: A Laboratory Analysis. The Journal of orthopaedic and sports physical therapy 2015;45(8):626-33 doi: 10.2519/jospt.2015.5653[published Online First: Epub Date]|.

91. Doherty C, Bleakley C, Hertel J, Caulfield B, Ryan J, Delahunt E. Dynamic balance deficits in individuals with chronic ankle instability compared to ankle sprain copers 1 year after a firsttime lateral ankle sprain injury. Knee surgery, sports traumatology, arthroscopy : official journal of the ESSKA 2015 doi: 10.1007/s00167-015-3744-z[published Online First: Epub Date]|.

92. Doherty C, Bleakley C, Hertel J, Caulfield B, Ryan J, Delahunt E. Single-leg drop landing movement strategies in participants with chronic ankle instability compared with lateral ankle sprain 'copers'. Knee surgery, sports traumatology, arthroscopy : official journal of the ESSKA 2015 doi: 10.1007/s00167-015-3852-9[published Online First: Epub Date]|.

93. Doherty C, Bleakley C, Hertel J, Caulfield B, Ryan J, Delahunt E. Locomotive biomechanics in persons with chronic ankle instability and lateral ankle sprain copers. Journal of science and medicine in sport / Sports Medicine Australia 2015 doi: 10.1016/j.jsams.2015.07.010[published Online First: Epub Date]|.

94. Doherty C, Bleakley C, Hertel J, et al. Inter-joint coordination strategies during unilateral stance following first-time, acute lateral ankle sprain: A brief report. Clinical biomechanics (Bristol, Avon) 2015;30(6):636-9 doi: 10.1016/j.clinbiomech.2015.04.012[published Online First: Epub Date]|.

95. Doherty C, Bleakley C, Hertel J, et al. Coordination and symmetry patterns during the drop vertical jump, 6-months after first-time lateral ankle sprain. Journal of orthopaedic research : official publication of the Orthopaedic Research Society 2015;33(10):1537-44 doi: 10.1002/jor.22915[published Online First: Epub Date]|.

96. Doherty C, Bleakley C, Hertel J, et al. Lower Limb Interjoint Postural Coordination One Year after First-Time Lateral Ankle Sprain. Medicine and science in sports and exercise 2015;47(11):2398405 doi: 10.1249/mss.0000000000000673[published Online First: Epub Date]|.

97. Nelson A, Collins C, Yard E, Fields S, Comstock R. Ankle injuries among united states high school sports athletes, 2005-2006. Journal of athletic training 2007;42(3):381-87

98. Swenson D, Yard E, Fields S, Comstock R. Patterns of recurrent injuries among US high school athletes, 2005-2008. American Journal of Sports Medicine 2009;37(8):1586-89

99. Yeung M, Chan K, So C. An epidemiological survey on ankle sprain. British journal of sports medicine 1994;28:112-16

100. Beynnon B, Murphy D, Alosa D. Predictive factors for lateral ankle sprains: A literature review. Journal of athletic training 2002;37(4):376-80

101. Bahr R, Bahr IA. Incidence of acute volleyball injuries: a prospective cohort study of injury mechanisms and risk factors. Scandinavian journal of medicine \& science in sports 1997;7(3):166-71

102. Zech A, Hubscher M, Vogt L, Banzer W, Hansel F, Pfeifer K. Neuromuscular training for rehabilitation of sports injuries: a systematic review. Medicine and science in sports and exercise 2009;41(10):1831-41 doi: 10.1249/MSS.0b013e3181a3cfod[published Online First: Epub Date]|.

103. Holme E, Magnusson SP, Becher K, Bieler T, Aagaard P, Kjaer M. The effect of supervised rehabilitation on strength, postural sway, position sense and re-injury risk after acute ankle ligament sprain. Scandinavian journal of medicine \& science in sports 1999;9(2):104-9 
104. Steib S, Zech A, Hentschke C, Pfeifer K. Fatigue-induced alterations of static and dynamic postural control in athletes with a history of ankle sprain. Journal of athletic training 2013;48(2):203-8 doi: 10.4085/1062-6050-48.1.08[published Online First: Epub Date]|.

105. Gribble PA, Hertel J, Denegar CR. Chronic ankle instability and fatigue create proximal joint alterations during performance of the Star Excursion Balance Test. International journal of sports medicine 2007;28(3):236-42

106. Gribble PA, Hertel J, Denegar CR, Buckley WE. The Effects of Fatigue and Chronic Ankle Instability on Dynamic Postural Control. Journal of athletic training 2004;39(4):321-29

107. Hertel J. Functional anatomy, pathomechanics, and pathophysiology of lateral ankle instability. Journal of athletic training 2002;37(4):364-75

108. Tropp H, Odenrick P, Gillquist J. Stabilometry recordings in functional and mechanical instability of the ankle joint. International journal of sports medicine 1985;6(3):180-2 doi: 10.1055/s-20081025836[published Online First: Epub Date]|.

109. Freeman M. Instability of the foot after injuries to the lateral ligament of the ankle. Journal of Bone and Joint Surgery 1965;47-B(4):669-77

110. Hertel J. Functional instability following lateral ankle sprain. Sports medicine (Auckland, N.Z.) 2000;29(5):361-71

111. Hiller C, Kilbreath S, Refshauge K. Chronic ankle instability: evolution of the model. Journal of athletic training 2011;46(2):133-41

112. Docherty C, Gansneder B, Arnold B, Hurwitz S. Development and reliability of the ankle instability instrument. Journal of athletic training 2006;41(2):154-58

113. Hiller C, Refshauge K, Bundy A, Herbert R, Kilbreath S. The Cumberland ankle instability tool: a report of validity and reliability testing. Archives of physical medicine and rehabilitation 2006;87(9):1235-41

114. Attenborough AS, Hiller CE, Smith RM, Stuelcken M, Greene A, Sinclair PJ. Chronic ankle instability in sporting populations. Sports medicine (Auckland, N.Z.) 2014;44(11):1545-56 doi: 10.1007/s40279-014-0218-2[published Online First: Epub Date]|.

115. Attenborough AS, Sinclair PJ, Sharp T, et al. A snapshot of chronic ankle instability in a cohort of netball players. Journal of science and medicine in sport / Sports Medicine Australia 2015 doi: 10.1016/j.jsams.2015.04.010[published Online First: Epub Date]|.

116. Tanen L, Docherty CL, Van Der Pol B, Simon J, Schrader J. Prevalence of chronic ankle instability in high school and division I athletes. Foot \& ankle specialist 2014;7(1):37-44 doi: 10.1177/1938640013509670[published Online First: Epub Date]|.

117. Simon J, Hall E, Docherty C. Prevalence of chronic ankle instability and associated symptoms in university dance majors: an exploratory study. Journal of dance medicine \& science : official publication of the International Association for Dance Medicine \& Science 2014;18(4):178-84 doi: 10.12678/1089-313x.18.4.178[published Online First: Epub Date]|.

118. Pourkazemi F, Hiller CE, Raymond J, Nightingale EJ, Refshauge KM. Predictors of chronic ankle instability after an index lateral ankle sprain: a systematic review. Journal of science and medicine in sport / Sports Medicine Australia 2014;17(6):568-73 doi: 10.1016/j.jsams.2014.01.005[published Online First: Epub Date]|.

119. Hubbard-Turner T, Turner MJ. Physical Activity Levels in College Students With Chronic Ankle Instability. Journal of athletic training 2015 doi: 10.4085/1062-6050-50.3.05[published Online First: Epub Date]|.

120. Hubbard-Turner T, Wikstrom EA, Guderian S, Turner MJ. An Acute Lateral Ankle Sprain Significantly Decreases Physical Activity across the Lifespan. Journal of sports science \& medicine 2015;14(3):556-61 
121. Kaur J, Sinha A. Prevalence of ankle sprain and service utilization among players of punjab. International Journal of Therapies and Rehabilitation Research 2015;4(1):16-24

122. Prado MP, Mendes AA, Amodio DT, Camanho GL, Smyth NA, Fernandes TD. A comparative, prospective, and randomized study of two conservative treatment protocols for first-episode lateral ankle ligament injuries. Foot \& ankle international 2014;35(3):201-6 doi: 10.1177/1071100713519776[published Online First: Epub Date]|.

123. Aiken AB, Pelland L, Brison R, Pickett W, Brouwer B. Short-term natural recovery of ankle sprains following discharge from emergency departments. The Journal of orthopaedic and sports physical therapy 2008;38(9):566-71 doi: 10.2519/jospt.2008.2811[published Online First: Epub Date]l.

124. Kerin F, Delahunt E. Physiotherapists' understanding of functional and mechanical insufficiencies contributing to chronic ankle instability. Athletic Training and Sports Health Care 2011;3(3):12530

125. Delahunt E, Caulfield B, Doherty C. Question 16: What Criteria Should Be Used to Diagnose a Patient With Chronic Ankle Instability? In: McKeon P, Wikstrom E, eds. Quick Questions in Ankle Sprains: Expert Advice in Sports Medicine. Thorofare, New Jersey, USA: Slack Incorporated, 2015.

126. Arnold B, DE LA Motte S, Linens S, Ross S. Ankle instability is associated with balance impairments: a meta-analysis. Medicine and Science in Sport and Exercise 2009;41(5):1048-62

127. Brown C, Bowser B, Simpson KJ. Movement variability during single leg jump landings in individuals with and without chronic ankle instability. Clinical Biomechanics 2012;27(1):52-63 doi: 10.1016/j.clinbiomech.2011.07.012[published Online First: Epub Date]|.

128. Brown CN, Padua DA, Marshall SW, Guskiewicz KM. Variability of motion in individuals with mechanical or functional ankle instability during a stop jump maneuver. Clinical Biomechanics 2009;24(9):762-68 doi: 10.1016/j.clinbiomech.2009.07.001[published Online First: Epub Date]|.

129. Brown CN, Padua DA, Marshall SW, Guskiewicz KM. Hip Kinematics During a Stop-Jump Task in Patients With Chronic Ankle Instability. Journal of athletic training 2011;46(5):461-67

130. Hubbard T, Kramer L, Denegar C, Hertel J. Contributing factors to chronic ankle instability. Foot and Ankle International 2007;28(3):343-54

131. Munn J, Sullivan S, Schneiders A. Evidence of sensorimotor deficits in functional ankle instability: A systematic review with meta-analysis. Journal of Science and Medicine in Sport 2010;13(1):2-12

132. Sefton J, Hicks-Little C, Hubbard T, et al. Sensorimotor function as a predictor of chronic ankle instability. Clinical Biomechanics 2009;24(5):451-58

133. Wikstrom EA, Tillman MD, Chmielewski TL, Cauraugh JH, Naugle KE, Borsa P. Discriminating Between Copers and People With Chronic Ankle Instability. Journal of athletic training 2012;47(2):136-42

134. Wikstrom EA, Tillman MD, Chmielewski TL, Cauraugh JH, Naugle KE, Borsa PA. Self-assessed disability and functional performance in individuals with and without ankle instability: a case control study. The Journal of orthopaedic and sports physical therapy 2009;39(6):458-67 doi: 10.2519/jospt.2009.2989[published Online First: Epub Date]|.

135. Witchalls J, Blanch P, Waddington G, Adams R. Intrinsic functional deficits associated with increased risk of ankle injuries: a systematic review with meta-analysis. British journal of sports medicine 2012;46(7):515-23 doi: 10.1136/bjsports-2011-090137[published Online First: Epub Date]|.

136. Witchalls J, Blanch P, Waddington G, Adams R. Intrinsic functional deficits associated with increased risk of ankle injuries: a systematic review with meta-analysis. British journal of sports medicine 2012;46(7):515-23 doi: 10.1136/bjsports-2011-090137[published Online First: Epub Date]|.

137. Chinn L, Dicharry J, Hertel J. Ankle kinematics of individuals with chronic ankle instability while walking and jogging on a treadmill in shoes. Physical therapy in sport : official journal of the 
Association of Chartered Physiotherapists in Sports Medicine 2013;14(4):232-9 doi: 10.1016/j.ptsp.2012.10.001[published Online First: Epub Date]|.

138. Drewes LK, McKeon PO, Paolini G, et al. Altered ankle kinematics and shank-rear-foot coupling in those with chronic ankle instability. Journal of sport rehabilitation 2009;18(3):375-88

139. Feger MA, Donovan L, Hart JM, Hertel J. Lower extremity muscle activation in patients with or without chronic ankle instability during walking. Journal of athletic training 2015;50(4):350-7 doi: 10.4085/1062-6050-50.2.06[published Online First: Epub Date]|.

140. Terada M, Bowker S, Thomas AC, et al. Alterations in stride-to-stride variability during walking in individuals with chronic ankle instability. Human movement science 2015;40:154-62 doi: 10.1016/j.humov.2014.12.004[published Online First: Epub Date]|.

141. Terada M, Pietrosimone B, Gribble PA. Individuals with chronic ankle instability exhibit altered landing knee kinematics: potential link with the mechanism of loading for the anterior cruciate ligament. Clinical biomechanics (Bristol, Avon) 2014;29(10):1125-30 doi: 10.1016/j.clinbiomech.2014.09.014[published Online First: Epub Date]|.

142. Terada M, Pietrosimone BG, Gribble PA. Alterations in neuromuscular control at the knee in individuals with chronic ankle instability. Journal of athletic training 2014;49(5):599-607 doi: 10.4085/1062-6050-49.3.28[published Online First: Epub Date]|.

143. Terada M, Harkey MS, Wells AM, Pietrosimone BG, Gribble PA. The influence of ankle dorsiflexion and self-reported patient outcomes on dynamic postural control in participants with chronic ankle instability. Gait \& posture 2014;40(1):193-7 doi: 10.1016/j.gaitpost.2014.03.186[published Online First: Epub Date]|.

144. Terada M, Pfile KR, Pietrosimone BG, Gribble PA. Effects of chronic ankle instability on energy dissipation in the lower extremity. Medicine and science in sports and exercise 2013;45(11):2120-8 doi: 10.1249/MSS.0b013e31829a3d0b[published Online First: Epub Date]|.

145. Gribble $P$, Robinson R. Differences in spatiotemporal landing variables during a dynamic stability task in subjects with CAI. Scandinavian journal of medicine \& science in sports 2010;20(1):e6371 doi: 10.1111/j.1600-0838.2009.00899.x[published Online First: Epub Date]|.

146. Gribble PA, Robinson RH. An examination of ankle, knee, and hip torque production in individuals with chronic ankle instability. Journal of strength and conditioning research / National Strength \& Conditioning Association 2009;23(2):395-400 doi: 10.1519/JSC.0b013e31818efbb2[published Online First: Epub Date]|.

147. Gribble PA, Robinson RH. Alterations in knee kinematics and dynamic stability associated with chronic ankle instability. Journal of athletic training 2009;44(4):350-5 doi: 10.4085/1062-605044.4.350[published Online First: Epub Date]|.

148. Ross SE, Guskiewicz KM. Examination of static and dynamic postural stability in individuals with functionally stable and unstable ankles. Clinical journal of sport medicine : official journal of the Canadian Academy of Sport Medicine 2004;14(6):332-8

149. Wikstrom EA, Bishop MD, Inamdar AD, Hass CJ. Gait termination control strategies are altered in chronic ankle instability subjects. Medicine and science in sports and exercise 2010;42(1):197205 doi: 10.1249/MSS.0b013e3181ad1e2f[published Online First: Epub Date]|.

150. Wikstrom EA, Fournier KA, McKeon PO. Postural control differs between those with and without chronic ankle instability. Gait \& posture 2010;32(1):82-6 doi: 10.1016/j.gaitpost.2010.03.015[published Online First: Epub Date]|.

151. Wikstrom EA, Tillman MD, Borsa PA. Detection of dynamic stability deficits in subjects with functional ankle instability. Medicine and science in sports and exercise 2005;37(2):169-75

152. Wikstrom EA, Tillman MD, Chmielewski TL, Cauraugh JH, Naugle KE, Borsa PA. Dynamic postural control but not mechanical stability differs among those with and without chronic ankle 
instability. Scandinavian journal of medicine \& science in sports 2010;20(1):e137-44 doi: 10.1111/j.1600-0838.2009.00929.x[published Online First: Epub Date]|.

153. Harkey M, McLeod M, Terada M, Gribble P, Pietrosimone B. Quadratic Association Between Corticomotor and Spinal-Reflexive Excitability and Self-Reported Disability in Participants with Chronic Ankle Instability. Journal of sport rehabilitation 2015 doi: 10-1123/jsr.20140282[published Online First: Epub Date]|.

154. Harkey M, McLeod M, Van Scoit A, et al. The immediate effects of an anterior-to-posterior talar mobilization on neural excitability, dorsiflexion range of motion, and dynamic balance in patients with chronic ankle instability. Journal of sport rehabilitation 2014;23(4):351-9 doi: 10.1123/jsr.2013-0085[published Online First: Epub Date]|.

155. McLeod MM, Gribble PA, Pietrosimone BG. Chronic Ankle Instability and Neural Excitability of the Lower Extremity. Journal of athletic training 2015;50(8):847-53 doi: 10.4085/1062-605050.4.06[published Online First: Epub Date]|.

156. Needle AR, Palmer JA, Kesar TM, Binder-Macleod SA, Swanik CB. Brain regulation of muscle tone in healthy and functionally unstable ankles. Journal of sport rehabilitation 2013;22(3):202-11

157. Needle AR, Swanik CB, Schubert M, et al. Decoupling of laxity and cortical activation in functionally unstable ankles during joint loading. European journal of applied physiology 2014;114(10):212938 doi: 10.1007/s00421-014-2929-3[published Online First: Epub Date]|.

158. Pietrosimone BG, Gribble PA. Chronic ankle instability and corticomotor excitability of the fibularis longus muscle. Journal of athletic training 2012;47(6):621-6 doi: 10.4085/1062-605047.6.11[published Online First: Epub Date]|.

159. Wikstrom EA, Hubbard-Turner T, McKeon PO. Understanding and treating lateral ankle sprains and their consequences: a constraints-based approach. Sports medicine (Auckland, N.Z.) 2013;43(6):385-93 doi: 10.1007/s40279-013-0043-z[published Online First: Epub Date]|.

160. Hass CJ, Bishop MD, Doidge D, Wikstrom EA. Chronic Ankle Instability Alters Central Organization of Movement. American Journal of Sports Medicine 2010;38(4):829-34 doi: 10.1177/0363546509351562[published Online First: Epub Date]|.

161. Klykken LW, Pietrosimone BG, Kim KM, Ingersoll CD, Hertel J. Motor-neuron pool excitability of the lower leg muscles after acute lateral ankle sprain. Journal of athletic training 2011;46(3):263-9

162. Van Deun S, Staes F, Stappaerts K, Janssens L, Levin O, Peers K. Relationship of chronic ankle instability to muscle activation patterns during the transition from double-leg to single-leg stance American Journal of Sports Medicine 2007;35(2):274-81

163. Doherty C, Bleakley C, Hertel J, Caulfield B, Ryan J, Delahunt E. Postural control strategies during single limb stance following acute lateral ankle sprain. Clinical biomechanics (Bristol, Avon) 2014;29(6):643-9 doi: 10.1016/j.clinbiomech.2014.04.012[published Online First: Epub Date]|.

164. Doherty C, Bleakley C, Hertel J, Caulfield B, Ryan J, Delahunt E. Lower extremity function during gait in participants with first time acute lateral ankle sprain compared to controls. Journal of electromyography and kinesiology : official journal of the International Society of Electrophysiological Kinesiology 2015;25(1):182-92 doi: 10.1016/j.jelekin.2014.09.004[published Online First: Epub Date]|.

165. Doherty C, Bleakley C, Hertel J, et al. Inter-joint coordination strategies during unilateral stance 6months following first-time lateral ankle sprain. Clinical biomechanics (Bristol, Avon) 2015;30(2):129-35 doi: 10.1016/j.clinbiomech.2014.12.011[published Online First: Epub Date]|.

166. Doherty C, Bleakley CM, Hertel J, Caulfield B, Ryan J, Delahunt E. Laboratory Measures of Postural Control During the Star Excursion Balance Test After Acute First-Time Lateral Ankle Sprain. Journal of athletic training 2015;50(6):651-64 doi: 10.4085/1062-6050-50.1.09[published Online First: Epub Date]|. 
167. Doherty C, Bleakley C, Hertel J, Caulfield B, Ryan J, Delahunt E. Balance failure in single limb stance due to ankle sprain injury: an analysis of center of pressure using the fractal dimension method. Gait \& posture 2014;40(1):172-6 doi: 10.1016/j.gaitpost.2014.03.180[published Online First: Epub Date]|.

168. Doherty C, Bleakley C, Hertel J, et al. Lower extremity coordination and symmetry patterns during a drop vertical jump task following acute ankle sprain. Human movement science 2014;38:34-46 doi: 10.1016/j.humov.2014.08.002[published Online First: Epub Date]|.

169. Collins M, Raleigh SM. Genetic risk factors for musculoskeletal soft tissue injuries. Medicine and sport science 2009;54:136-49 doi: 10.1159/000235701[published Online First: Epub Date]|.

170. September AV, Schwellnus MP, Collins M. Tendon and ligament injuries: the genetic component. British journal of sports medicine 2007;41(4):241-6; discussion 46 doi: 10.1136/bjsm.2006.033035[published Online First: Epub Date]|.

171. Shang X, Li Z, Cao X, et al. The association between the ACTN3 R577X polymorphism and noncontact acute ankle sprains. Journal of sports sciences 2015;33(17):1775-9 doi: 10.1080/02640414.2015.1012098[published Online First: Epub Date]|.

172. Saltzman CL, Zimmerman B, O'Rourke M, Brown TD, Buckwalter JA, Johnston R. Impact of comorbidities on the measurement of health in patients with ankle osteoarthritis. Journal of Bone and Joint Surgery-American Volume 2006;88A(11):2366-72 doi: 10.2106/jbjs.f.00295[published Online First: Epub Date]|.

173. Brown T, Johnston R, Saltzman C, Marsh J, Buckwalter J. Posttraumatic osteoarthritis: a first estimate of incidence, prevalence, and burden of disease. Journal of Orthopaedic Trauma 2006;20(10):739-44

174. Saltzman CL, Salamon ML, Blanchard GM, et al. Epidemiology of ankle arthritis: report of a consecutive series of 639 patients from a tertiary orthopaedic center. The lowa orthopaedic journal 2005;25:44-6

175. Lofvenberg R, Karrholm J, Lund B. The outcome of nonoperated patients with chronic lateral instability of the ankle: a 20-year follow-up study. Foot \& ankle international 1994;15(4):165-9

176. Canale ST, Belding RH. Osteochondral lesions of the talus. The Journal of bone and joint surgery. American volume 1980;62(1):97-102

177. Harrington KD. Degenerative arthritis of the ankle secondary to long-standing lateral ligament instability. The Journal of bone and joint surgery. American volume 1979;61(3):354-61

178. Hintermann B, Boss A, Schafer D. Arthroscopic findings in patients with chronic ankle instability. The American journal of sports medicine 2002;30(3):402-9

179. Ferkel RD, Chams RN. Chronic lateral instability: arthroscopic findings and long-term results. Foot \& ankle international 2007;28(1):24-31 doi: 10.3113/fai.2007.0005[published Online First: Epub Date]|.

180. Kibler WB. Arthroscopic findings in ankle ligament reconstruction. Clinics in sports medicine 1996;15(4):799-804

181. Komenda GA, Ferkel RD. Arthroscopic findings associated with the unstable ankle. Foot \& ankle international 1999;20(11):708-13

182. Sammarco GJ, DiRaimondo CV. Surgical treatment of lateral ankle instability syndrome. The American journal of sports medicine 1988;16(5):501-11

183. Sugimoto K, Takakura Y, Okahashi K, Samoto N, Kawate K, Iwai M. Chondral injuries of the ankle with recurrent lateral instability: an arthroscopic study. The Journal of bone and joint surgery. American volume 2009;91(1):99-106 doi: 10.2106/jbjs.g.00087[published Online First: Epub Date]|. 
184. Takao M, Uchio Y, Naito K, Fukazawa I, Ochi M. Arthroscopic assessment for intra-articular disorders in residual ankle disability after sprain. The American journal of sports medicine 2005;33(5):686-92 doi: 10.1177/0363546504270566[published Online First: Epub Date]|.

185. van Dijk CN, Bossuyt PM, Marti RK. Medial ankle pain after lateral ligament rupture. The Journal of bone and joint surgery. British volume 1996;78(4):562-7

186. van Ochten JM, Mos MC, van Putte-Katier N, et al. Structural abnormalities and persistent complaints after an ankle sprain are not associated: an observational case control study in primary care. The British journal of general practice : the journal of the Royal College of General Practitioners 2014;64(626):e545-53 doi: 10.3399/bjgp14X681349[published Online First: Epub Date]|.

187. van Putte-Katier N, van Ochten JM, van Middelkoop M, Bierma-Zeinstra SM, Oei EH. Magnetic resonance imaging abnormalities after lateral ankle trauma in injured and contralateral ankles. European journal of radiology 2015;84(12):2586-92 doi: 10.1016/j.ejrad.2015.09.028[published Online First: Epub Date]|.

188. Sanmarco GJ, DiRaimnoda CV. Surgical treatment of lateral ankle instability syndrome. Am J Sports Med 1988;16:501-11

189. Golditz T, Welsch GH, Pachowsky M, Hennig FF, Pfeifer K, Steib S. A multimodal approach to ankle instability: Interrelations between subjective and objective assessments of ankle status in athletes. Journal of orthopaedic research : official publication of the Orthopaedic Research Society 2015 doi: 10.1002/jor.23039[published Online First: Epub Date]|.

190. Arnold BL, Wright CJ, Ross SE. Functional ankle instability and health-related quality of life. Journal of athletic training 2011;46(6):634-41

191. Houston MN, Van Lunen BL, Hoch MC. Health-related quality of life in individuals with chronic ankle instability. Journal of athletic training 2014;49(6):758-63 doi: 10.4085/1062-605049.3.54[published Online First: Epub Date]|.

192. Simon JE, Docherty CL. Current health-related quality of life is lower in former Division I collegiate athletes than in non-collegiate athletes. The American journal of sports medicine 2014;42(2):423-9 doi: 10.1177/0363546513510393[published Online First: Epub Date]|.

193. Houston MN, Hoch JM, Gabriner ML, Kirby JL, Hoch MC. Clinical and laboratory measures associated with health-related quality of life in individuals with chronic ankle instability. Physical therapy in sport : official journal of the Association of Chartered Physiotherapists in Sports Medicine 2015;16(2):169-75 doi: 10.1016/j.ptsp.2014.10.006[published Online First: Epub Date]|.

194. Houston MN, Hoch JM, Hoch MC. Patient-Reported Outcome Measures in Individuals With Chronic Ankle Instability: A Systematic Review. Journal of athletic training 2015 doi: 10.4085/1062-605050.9.01[published Online First: Epub Date]|.

195. Wikstrom EA, Hubbard-Turner T, Woods S, Guderian S, Turner MJ. Developing a mouse model of chronic ankle instability. Medicine and science in sports and exercise 2015;47(4):866-72 doi: 10.1249/mss.0000000000000466[published Online First: Epub Date]|.

196. Verhagen RA, de Keizer G, van Dijk CN. Long-term follow-up of inversion trauma of the ankle. Archives of orthopaedic and trauma surgery 1995;114(2):92-6

197. Lee M, Kwon JW, Choi WJ, Lee JW. Comparison of Outcomes for Osteochondral Lesions of the Talus With and Without Chronic Lateral Ankle Instability. Foot \& ankle international 2015 doi: 10.1177/1071100715581477[published Online First: Epub Date]|.

198. Valderrabano V, Hintermann B, Horisberger M, Fung T. Ligamentous posttraumatic ankle osteoarthritis. American Journal of Sports Medicine 2006;34(4):612-20 
199. Hubbard-Turner T, Wikstrom EA, Guderian S, Turner MJ. Acute ankle sprain in a mouse model. Medicine and science in sports and exercise 2013;45(8):1623-8 doi: 10.1249/MSS.0b013e3182897d25[published Online First: Epub Date]|.

200. Hershkovich O, Tenenbaum S, Gordon B, et al. A large-scale study on epidemiology and risk factors for chronic ankle instability in young adults. The Journal of foot and ankle surgery : official publication of the American College of Foot and Ankle Surgeons 2015;54(2):183-7 doi: 10.1053/j.jfas.2014.06.001[published Online First: Epub Date]|.

201. Simon J, Docherty C. Current health-related quality of life in older adults with chronic ankle instability British journal of sports medicine 2015;49(Supplement 1):A10 